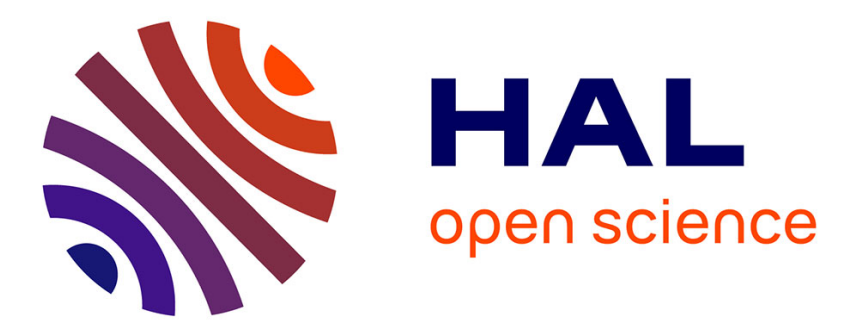

\title{
Outer membrane lipoprotein DolP interacts with the BAM complex and promotes fitness during envelope stress response
}

David Ranava, Yiying Yang, Luis Orenday-Tapia, François Rousset, Catherine Turlan, Lun Cui, Violette Morales, Cyril Moulin, Gladys Munoz, Jerome

Rech, et al.

\section{To cite this version:}

David Ranava, Yiying Yang, Luis Orenday-Tapia, François Rousset, Catherine Turlan, et al.. Outer membrane lipoprotein DolP interacts with the BAM complex and promotes fitness during envelope stress response. 2020. hal-03039259

\section{HAL Id: hal-03039259 \\ https://hal.science/hal-03039259}

Preprint submitted on 3 Dec 2020

HAL is a multi-disciplinary open access archive for the deposit and dissemination of scientific research documents, whether they are published or not. The documents may come from teaching and research institutions in France or abroad, or from public or private research centers.
L'archive ouverte pluridisciplinaire HAL, est destinée au dépôt et à la diffusion de documents scientifiques de niveau recherche, publiés ou non, émanant des établissements d'enseignement et de recherche français ou étrangers, des laboratoires publics ou privés. 
1 Outer membrane lipoprotein DoIP interacts with the BAM complex and 2 promotes fitness during envelope stress response

5 David Ranava ${ }^{1, \S}$, Yiying Yang ${ }^{1, \S}$, Luis Orenday-Tapia ${ }^{1, \S}$, François Rousset ${ }^{2}$, 6 Catherine Turlan ${ }^{1}$, Lun Cui ${ }^{2}$, Violette Morales ${ }^{1}$, Cyril Moulin', Gladys Munoz ${ }^{1}$, 7 Jérôme Rech ${ }^{1}$, Anne Caumont-Sarcos ${ }^{1}$, Cécile Albenne ${ }^{1}$, David Bikard ${ }^{2}$, Raffaele $8 \operatorname{leva}^{1^{*}}$

9

$10{ }^{1}$ Laboratoire de Microbiologie et Génétique Moléculaires (LMGM), Centre de 11 Biologie Intégrative (CBI), Université de Toulouse, CNRS, UPS, Toulouse 31062, 12 France.

13 2Synthetic Biology Group, Microbiology Department, Institut Pasteur, Paris 75015, 14 France.

15 §These authors contributed equally to this paper.

17 *Correspondance to:

18 Raffaele leva, raffaele.ieva@univ-tlse3.fr 


\section{Abstract}

In Gram-negative bacteria, coordinated remodelling of the outer membrane $(\mathrm{OM})$ and the peptidoglycan is crucial for envelope integrity. Envelope stress caused by unfolded $\mathrm{OM}$ proteins (OMPs) activates sigmaE $\left(\sigma^{\mathrm{E}}\right)$ in

26 Enterobacteria. $\sigma^{\mathrm{E}}$ upregulates OMP biogenesis factors, including the $\beta$-barrel assembly machinery (BAM) that catalyzes OMP-folding. Elevated $\sigma^{\mathrm{E}}$ activity, however, can be detrimental for OM integrity. Here we report that DolP (YraP), a $\sigma^{\mathrm{E}}$ upregulated OM lipoprotein important for envelope integrity, is a novel interactor of BAM and we demonstrate that OM-assembled BamA is a critical determinant of the BAM-DolP complex. Mid-cell recruitment of DolP had been previously associated to activation of septal peptidoglycan remodelling during cell division, but its role during envelope stress was unknown. We now show that DolP promotes cell fitness upon stress-induced activation of $\sigma^{\mathrm{E}}$ and opposes a detrimental effect caused by the overaccumulation of BAM in the OM. During envelope stress, DolP loses its association with the mid-cell, thus suggesting a possible link between envelope stress caused by impaired OMP biogenesis and the regulation of a late step of cell division. 
Introduction

The outer membrane (OM) of Gram-negative bacteria forms a protective barrier against harmful compounds, including several antimicrobials. This envelope structure surrounds the inner membrane and the periplasm that contains the peptidoglycan, a net-like structure made of glycan chains and interconnecting peptides. During cell division, the multi-layered envelope structure is remodelled by the divisome machinery ${ }^{1}$. At a late step of division, septal peptidoglycan synthesized by the divisome undergoes splitting, initiating the formation of the new poles of adjacent daughter cells. Finally, remodelling of the OM barrier completes formation of the new poles in the cell offspring. The mechanisms by which cells coordinate OM remodelling with peptidoglycan splitting, preserving the permeability barrier of this protective membrane, are ill-defined ${ }^{2}$.

Integral outer membrane proteins (OMPs) are crucial to maintain the OM permeability barrier. OMPs fold into amphipathic $\beta$-barrel structures that span the $\mathrm{OM}$ and carry out a variety of tasks. Porins are OMPs that facilitate the diffusion of small metabolites. Other OMPs function as cofactor transporters, secretory channels, or machineries for the assembly of proteins and lipopolysaccharide (LPS) ${ }^{3,4}$, a structural component of the external OM leaflet that prevents the diffusion of noxious chemicals ${ }^{4}$. The $\beta$-barrel assembly machinery (BAM) is a multi-subunit complex that mediates the folding and membrane insertion of OMPs transiting through the periplasm ${ }^{5,6}$. The essential and evolutionarily conserved BamA insertase subunit is an OMP consisting of an amino (N)-terminal periplasmic domain made of polypeptide transport-associated (POTRA or P) motifs and a carboxy (C)terminal 16-stranded $\beta$-barrel membrane domain that catalyzes OMP biogenesis ${ }^{7,8}$. The flexible pairing of $\beta$-strands 1 and 16 of the BamA $\beta$-barrel controls a lateral gate connecting the interior of the barrel towards the surrounding lipid bilayer ${ }^{9-12}$. 
Conformational dynamics of the BamA $\beta$-barrel region proximal to the lateral gate is thought to locally increase the entropy of the surrounding lipid bilayer ${ }^{9,13,14}$ and assist the insertion of nascent OMPs into the OM ${ }^{11,15,16}$. The $\mathrm{N}$-terminal periplasmic portion of BamA from the enterobacterium Escherichia coli contains five POTRA motifs that serve as a scaffold for four lipoproteins, BamBCDE, which assist BamA during OMP biogenesis ${ }^{17-19}$. The $\mathrm{N}$-terminal POTRA motif is also the docking site of the periplasmic chaperone SurA ${ }^{20}$. Together with the chaperones Skp and DegP, SurA contributes to monitor unfolded OMPs transported into the periplasm by the inner membrane general secretory (Sec) pathway ${ }^{21,22}$.

Defective OMP assembly causes periplasmic accumulation of unfolded protein transport intermediates. This envelope stress is signalled across the inner membrane to induce the sigmaE $\left(\sigma^{\mathrm{E}}\right)$-mediated transcriptional response ${ }^{23}$. In the absence of stress, $\sigma^{\mathrm{E}}$ is sequestered by the inner membrane-spanning RseA factor. By-products of misfolded OMP turnover activate degradation of RseA, liberating $\sigma^{\mathrm{E}}$ 24. The $\sigma^{\mathrm{E}}$ response copes with stress i) by upregulating genes involved in OMP biogenesis, such as the bam genes ${ }^{25}$, and ii) by lowering the OMP biogenesis burden via a post-transcriptional mechanism ${ }^{26}$. Whereas $\sigma^{\mathrm{E}}$ is essential ${ }^{27}$, a tight control of cytosolic $\sigma^{\mathrm{E}}$ availability is necessary for optimal cell fitness and to prevent a potentially detrimental effect on the envelope ${ }^{28-31}$. Remarkably, the functions of a number of genes upregulated by $\sigma^{\mathrm{E}}$ remains unknown. Among those, yraP encodes a $\sim 20 \mathrm{kDa}$ OM-anchored lipoprotein largely conserved in $\gamma$ and $\beta$ proteobacteria ${ }^{32-}$ 36. YraP is crucial for OM integrity ${ }^{34}$ and pathogenicity ${ }^{32}$. A recent study showed that YraP localizes at the mid-cell during a late step of cell division, where it contributes to the regulation of septal peptidoglycan splitting by an unknown mechanism ${ }^{33}$. These observations do not explain why YraP is upregulated in response to $\sigma^{\mathrm{E}}$ activation and how YraP helps coping with envelope stress. would place an additional burden on the already-complicated envelope reshaping 
96 process faced by cells. It remains unknown whether stress caused by unfolded

97 OMPs influences envelope remodelling at the forming poles of two adjacent 98 daughter cells. Here we present a functional investigation of yraP prompted by a 99 genome-wide synthetic-defect screen. We demonstrate genetic interactions of yraP

100 with bam genes and we provide evidence that YraP can associate with the BAM 101 complex via an interaction with the BamA subunit. YraP is not critical for OMP 102 assembly but promotes fitness upon activation of the $\sigma^{\mathrm{E}}$ response. Upon envelope 103 stress or when BAM overaccumulates in the OM, YraP loses its association with the 104 mid-cell, thus suggesting a possible link between the envelope stress response and 105 septal peptidoglycan hydrolysis during a late step of cell division. Hence, we 106 propose to rename YraP as DolP (division- and $\underline{\mathrm{OM}}$ stress-associated lipoprotein). 
Results

A genome-wide synthetic-defect screen identifies doIP genetic interactions

The mutant allele $\Delta$ dolP::kan ${ }^{37}$ was introduced into E. coli BW25113 by P1

111 transduction. The resulting $\Delta$ dolP strain grew normally on LB medium (Figs. S1A

112 and S1B), but was highly susceptible to vancomycin (Figs. 1A and S1B). This

113 antibiotic is normally excluded from the OM of wild-type cells but inhibits growth of

114 cells lacking OMP biogenesis factors such as skp and surA (Fig. S1B). The expression of C-terminally fused DolP protein variants in place of its wild-type form restored vancomycin resistance (Fig. 1A and Fig. S1C). This result supports the notion that DolP is important for envelope integrity ${ }^{33-36}$. However, the role of DolP during envelope stress remains poorly understood.

A previous study showed that lack of DolP causes a severe growth defect in a surA deletion strain, however the cause of this synthetic phenotype has remained unclear $^{34}$. To gain insights into the role of DolP, we subjected $\Delta d o l P$ cells to a genome-wide synthetic-defect screen exploiting a Clustered Regularly Interspersed Short Palindromic Repeat interference (CRISPRi) approach. Targeting of the catalytically inactive dCas9 nuclease by gene-specific single guides RNAs (sgRNAs) enables gene repression (Fig. 1B) ${ }^{38}$. The EcoWG1 sgRNA library

126 targeting the entire genome of $E$. coli MG1655 ${ }^{39}$ was introduced into isogenic $\Delta d o / P$

127 or dolP $P^{+}$MG1655-derivative strains. The fitness of each knockdown was then 128 compared in these backgrounds by deep-sequencing of the sgRNA library after $\sim 17$ growth generations. The outputs obtained from two independent tests were highly

130 reproducible (Fig. S2A). A strong fitness defect in the $\Delta$ doIP strain was caused by 131 the targeting of envC (Fig. 1C, Fig. S2B and Tables S1 and S2), followed by the

132 targeting of fts $X$ and ftsE (Fig. 1C, Tables S1 and S2). A validation growth test 133 showed that the synthetic fitness defect observed for $\Delta d o l P$ cells was caused by 134 dCas9-dependent silencing of fts $X$ and envC (Fig. 1D, panels 6 and 7). The ABC 
135 transporter-like complex FtsE/FtsX has multiple roles in organizing the cell

136 divisome, including the recruitment of periplasmic EnvC, a LytM domain-containing

137 factor required for the activation of amidases that hydrolyse septal peptidoglycan ${ }^{40}$.

138 This peptidoglycan remodelling reaction is mediated by two sets of highly controlled

139 and partially redundant amidases, $A m i A / A m i B$ and $A m i C{ }^{41,42}$. Whereas AmiA and

$140 \mathrm{AmiB}$ are activated at the inner membrane/peptidoglycan interface by the

141 coordinated action of FtsE/FtsX and EnvC, activation of AmiC requires the OM-

142 anchored LytM domain-containing lipoprotein NIpD 43,44. Under laboratory

143 conditions, the activity of only one of these two pathways is sufficient for septal

144 peptidoglycan splitting, whereas inhibition of both pathways leads to formation of

145 chains of partially divided cells, i.e. cells that have begun to divide but are blocked

146 at the step of septal peptidoglycan splitting ${ }^{44}$. A recent report showed that dolP is

147 necessary to complete septal peptidoglycan splitting and to promote cell separation

148 when the AmiA/AmiB pathway is inactive, somehow linking DolP to AmiC activation

$149{ }^{33}$. Thus, the reduced fitness caused by silencing of env $C$, ftsE or fts $X$ in $\triangle d o l P$ cells

150 (Fig. 1C) may be explained by impaired cell separation when both the AmiA/AmiB

151 and the AmiC pathways are not active. In keeping with this notion, amiA itself was

152 found among the negative fitness hits of the CRISPRi screen (Fig. 1C). amiB was

153 not a hit (Table S2), probably because AmiA is sufficient to split septal 154 peptidoglycan in the absence of other amidases ${ }^{45}$.

155 Most importantly, the CRISPRi approach identified novel dolP-genetic

156 interactions that had a score similar to that obtained for amiA (Fig. 1C). These

157 included an interaction with $r s e A$, encoding the inner membrane $\sigma^{\mathrm{E}}$-sequestering

158 factor, as well as with bamD, encoding an essential subunit of the BAM complex

$159{ }^{34,46}$. In accordance with the screen output, a serial dilution assay confirmed that 160 silencing of bamD (as well as bamE, encoding a stoichiometric interactor of BamD)

161 causes a fitness defect in cells lacking DolP (Fig. 1D, panels 8 and 9). In addition,

162 the interaction of dolP with $r s e A$ was confirmed in the genetic background of a 
BW25113 strain (Fig. 1E). Further genes, involved in OMP biogenesis and more generally in protein secretion, had a lower interaction score (Table S2 and Fig. S2C) and are highlighted in Fig. 1C. These comprise bamA, the OMP chaperoneencoding gene surA, as well as the genes encoding the Sec ancillary complex SecDF-YajC that contributes to efficient secretion of proteins including OMPs ${ }^{22}$ and that was shown to interact with the BAM complex ${ }^{47,48}$. Collectively, the results of the CRISPRi screen indicate that the function of DolP is particularly critical for cell fitness upon inactivation of septal peptidoglycan hydrolysis by AmiA, as well as when the assembly of proteins in the OM is impaired.

DolP improves cell fitness when the OM undergoes stress

At a first glance, the newly identified genetic interaction between dolP and bamD (Figs. 1C and 1D) points to a possible role of DolP in OMP biogenesis. However, the overall protein profile of the crude envelope fraction was not affected by the deletion of dolP (Fig. S3A, lanes 1-4). OMPs, such as the very abundant

$178 \mathrm{OmpA}$ and $\mathrm{OmpC}{ }^{49}$, can be recognized by their characteristic heat-modifiable migration patterns when separated by SDS-PAGE ${ }^{50}$ (Fig. S3 A-D). The levels of

180 OmpA (Fig. S3B), LamB (Fig. S3C) and OmpC (Fig. S3D) were not affected in

$181 \Delta$ dolP samples. Similarly, the assembly kinetics of an autotransporter OMP was not impaired (Fig. S3E). Importantly, the levels of proteins encoded by $\sigma^{\mathrm{E}}$-upregulated genes, such as BamA and BamE, were not increased in $\Delta$ dolP cells (Fig. 2A), indicating a wild-type-like $\sigma^{\mathrm{E}}$ activity in this strain. The envelope protein profiles were not affected also when dolP was deleted in cells lacking one of the OMP periplasmic chaperones Skp or DegP (Fig. S3A, lanes 5-12), suggesting that DolP does not play a function redundant with that of these periplasmic factors. Taken together, these observations suggest that DolP is not crucial for efficient OMP

189 biogenesis. The genetic interaction of dolP with bamD and surA (Fig. 1C) may also 190 suggest that DolP is required for optimal survival when the OM undergoes 
191 modifications caused by activation of the $\sigma^{\mathrm{E}}$ response ${ }^{34,46,51}$. This hypothesis is

192 supported by the observation that $\sigma^{\mathrm{E}}$ activation caused by $r$ seA silencing or deletion 193 worsens the fitness of $\Delta d o l P$ cells (Figs. $1 \mathrm{C}$ and $1 \mathrm{E}$ ).

194 To further test the importance of DolP under envelope stress conditions, we 195 deleted dolP in a strain lacking $b a m B$, which was identified with a lower genetic 196 score by the CRISPRi approach (Table S2). In $\triangle$ bamB cells, the $\sigma^{\mathrm{E}}$ response is 197 partially activated ${ }^{19,52}$, causing the upregulation of bam genes (Fig. 2B). A strain 198 carrying the simultaneous deletion of dolP and bamB was viable but growthdefective. Normal growth was restored by ectopic expression of a C-terminally polyhistidine tagged DolP protein variant (Fig. 2C). The $\Delta$ bamB envelope protein profile presented a marked reduction of the major heat-modifiable OMPs, OmpA and OmpC, however the concomitant lack of DolP did not enhance this OMP defect (Fig. S3A, lanes 13-18). Notably, phase-contrast analysis of the same $\Delta d o l P \Delta b a m B$ strain revealed a number of cells with altered morphology (Fig. 2D). This result suggests that the reduced fitness of $\triangle d o l P \Delta b a m B$ cells cannot be ascribed to an exacerbation of the OMP biogenesis defect already caused by lack of BamB, pointing to a different role of DolP under envelope stress conditions.

DolP promotes growth in cells with increased levels of BAM complex. The $\sigma^{\mathrm{E}}$ response leads to alteration of the $\mathrm{OM}$ protein content, with an

211 increase of the level of the BAM complex and a reduction of numerous other 212 proteins, including the most abundant OMPs and some lipoproteins ${ }^{25,53,54}$. To gain 213 further insights into the role of DolP during activation of the $\sigma^{\mathrm{E}}$ response, we 214 explored the effect of prolonged overproduction of BAM. To this end, the genes 215 encoding wild-type BamABCD and a C-terminally polyhistidine-tagged BamE 216 protein variant were ectopically expressed via the isopropylthiogalactoside (IPTG)217 inducible trc promoter $\left(\mathrm{P}_{\text {trc }}\right)$ as a transcriptional unit, adapting a previously 218 established method ${ }^{55}$. With $400 \mu \mathrm{M}$ IPTG, the concentration of BAM complex that 
219 accumulated in the membrane fraction was roughly similar to the concentration of

220 the major OMPs OmpA or OmpC (Fig. 3A, lane 2). Importantly, we noticed that

221 prolonged BAM overproduction caused a partial detrimental effect in the wild-type

222 BW25113 strain (Fig. 3B). The excess of BamA was responsible for impaired

223 growth, as the excess of different subsets of BAM subunits that did not include

224 BamA or an excess of OmpA obtained using a similar overproduction plasmid (see also the subsequent description of Fig. S7B) had no detectable effects in our growth tests (Fig. 3B). The detrimental effect of BAM overproduction was caused by the overaccumulation of BamA in the $\mathrm{OM}$, as the overproduction of an assemblydefective BamA variant, BamA ${ }^{\Delta P 1}$, that lacks the $\mathrm{N}$-terminal POTRA1 motif and largely accumulates in the periplasm ${ }^{20}$, did not impair growth to the same extent (Figs. S4A-C). Even a slight increment of BAM, due to the leaky transcriptional activity of the trc promoter (Fig. 3A, lane 1) caused a mild but noticeable deterioration of the $\mathrm{OM}$ permeability barrier to vancomycin (Fig. $3 \mathrm{C}$ ), suggesting that a small increment in BAM levels can enhance the permeability of the OM. Strikingly, in the absence of vancomycin, we noticed that the detrimental effect caused by IPTG-induced OM overaccumulation of BAM was more severe in a $\Delta d o l P$ strain (Fig. 3D). This difference was particularly evident with $200 \mu \mathrm{M}$ IPTG, which had only a minor inhibitory effect on the growth of wild-type cells but strongly

238 impaired the growth of a $\Delta d o l P$ strain. Similar to dolP, skp is upregulated by $\sigma^{\mathrm{E}}$ and its deletion causes sensitivity to vancomycin (Fig. S1B). In contrast to $\Delta d o l P$, a $\Delta s k p$ strain harbouring the same BAM overproduction plasmid could grow as the wild-

241 type reference (Fig. 3D), suggesting a specific effect of DolP in supporting growth when BAM is overproduced.

DoIP interacts with BamA assembled in the OM

The observed interaction between dolP and bam genes prompted us to investigate whether DoIP physically interacts with the BAM complex. To this end, a 
construct encoding C-terminally protein A-tagged DolP was ectopically expressed in $\Delta d o l P$ cells. The envelope of cells expressing DolP ${ }^{\text {ProtA }}$ was solubilized using digitonin as main mild-detergent component prior to lgG-affinity chromatography (Fig. 4A, coomassie staining). Site-specific enzymatic cleavage of an amino acid linker between DolP and the protein A tag was used for protein elution. Notably, BamA, BamC, BamD and BamE were immunodetected in the elution fraction of protein A-tagged DolP (Fig. 4A, lane 3). In contrast, the inner membrane protein

254 CyoA and cytosolic RpoB were not detected. Next, BAM ${ }^{\text {ProtA }}$ (consisting of wild-type BamABCD and a C-terminally protein A-tagged BamE protein variant) was ectopically overproduced to isolate the BAM complex via IgG-affinity purification (Fig. 4B, Coomassie staining). Importantly, in addition to the BamE bait and other subunits of the BAM complex, DolP was also immunodetected in the elution fraction (Fig. 4B, lane 3). Other proteins of the bacterial envelope (Skp, OmpA, and $F_{1} \beta$ of the $F_{1} F_{O}$ ATP synthase) or cytosolic RpoB were not detected (Fig. 4B). Taken together, our native pull-down analysis indicates that DoIP and BAM have affinity for each other.

To explore whether the central BAM subunit, BamA, is a critical determinant of the BAM-DolP interaction, we performed Ni-affinity purification using the solubilized envelope fraction obtained from cells overproducing BamA and Cterminally polyhistidine-tagged DolP. Under these conditions, BamA was efficiently co-eluted together with DolP ${ }^{\text {His }}$, demonstrating that BamA and DolP can interact even in the absence of stoichiometric amounts of the BAM lipoproteins (Fig. 4C, coomassie staining). To assess if the interaction of DolP and BAM takes place at 270 the OM, DolP ${ }^{\text {His }}$ was overproduced together with the assembly-defective form 271 BamA $^{\Delta P 1}$. When expressed together with DolP ${ }^{\text {His }}$, assembly-defective BamA ${ }^{\Delta P 1}$ was 272 highly depleted in the corresponding eluate (Fig. 4C, lane 7), even though BamA ${ }^{\Delta P 1}$ 273 was only marginally reduced in the crude envelope fraction with respect to wild-type 274 BamA (Fig. 4C, lane 3). In contrast to $B a m A^{\Delta P 1}$, the $B a m A^{\Delta P 2}$ variant, which is 
275 efficiently assembled into the OM (Fig. S4), was co-eluted to a similar extent as 276 wild-type BamA (Fig. 4C, lane 8). This result indicates that DolP has affinity for OM277 assembled BamA.

In seeking a detergent that would interfere with the interaction of BAM and 279 DolP, and allow their purification as separate components, we solubilized the envelope fraction with increasing amounts of $n$-dodecyl $\beta$-D-maltoside (DDM), a detergent previously used to isolate the native BAM complex ${ }^{55}$. At concentrations of DDM between $0.3 \%(\mathrm{w} / \mathrm{v})$ and $1 \%(\mathrm{w} / \mathrm{v})$, we observed a drastic reduction in the amounts of BAM subunits that were co-eluted with DolP ${ }^{\text {His }}$ (Fig. 4D), indicating that the BAM-DolP interaction is sensitive to DDM. We thus used $1 \%(w / v)$ DDM to extract and purify His-tagged DolP or His-tagged BAM as separate components (Fig. 4E). When analyzed by blue native-PAGE and immunoblotting, purified DolP gave rise to a diffused signal at around $450 \mathrm{kDa}$ (Fig. 4F, lane 1), suggesting a dynamic multimeric organization of this protein. Purified BAM migrated as expected at $250 \mathrm{kDa}$ (Fig. 4F, lane 7). When roughly equimolar amounts of purified BAM and DolP were pre-incubated in the presence of a low DDM concentration and subsequently resolved by blue native-PAGE, a complex with an apparent molecular weight higher than that of the BAM complex was detected with both anti-BamA and anti-DolP specific antibodies (Fig. 4F, lanes 3 to 6). Taken together our results demonstrate that the BAM complex and DolP interact to form a larger complex and that OM-assembled BamA is a critical determinant of this interaction. Only a portion of BAM and DolP associate to form the BAM-DolP complex, indicating that the interaction is substoichiometric.

\section{BamA overaccumulation in the OM reduces DolP mid-cell localization}

In light of our observation that DolP interacts with BAM, we asked whether

301 the envelope localization patterns of DoIP and BAM are reciprocally linked. First, we 302 monitored the effect of DolP expression on the localization of the chromosomally 
encoded BamD ${ }^{\text {mCherry }}$ subunit of the BAM complex. This protein generated a

304 fluorescence signal throughout the envelope that was not affected by the lack or the 305 overproduction of DolP (Fig. S5). Next, we checked the effect of BAM overaccumulation in the OM on DoIP localization. DoIP associates with the OM and accumulates at mid-cell during a late step of cell division ${ }^{33}$. To monitor the localization of DolP, we used a strain harbouring a chromosomal dolP-gfp fusion (Fig. 1A). The localization of the DolP ${ }^{\text {GFP }}$ fusion protein (Fig. S6A) was analyzed concomitantly with other two chromosomally-encoded markers of the division septum, ZipA ${ }^{\text {mCherry }}$ or NIpD ${ }^{\text {mCherry }}$. ZipA is involved in an early step of divisome assembly and accumulates at division sites before, as well as, during envelope constriction (Fig. S6B) ${ }^{56}$. Instead, NIpD is a late marker of cell division involved in

314 the activation of AmiC and accumulates at septa that are already undergoing 315 constriction (Fig. S6C) ${ }^{42,44}$. DolP ${ }^{\text {GFP }}$ accumulated at mid-cell sites where the 316 envelope appeared invaginated, showing a localization pattern similar to that of

$317 \mathrm{NlpD}^{\text {mCherry }}$ (Fig. S6C) ${ }^{33}$. We investigated the effect of short-lived (1 hour) BAM 318 overproduction on DolP ${ }^{\text {GFP }}$ localization. Strikingly, we found that BAM 319 overproduction depleted DolP ${ }^{\text {GFP }}$ from mid-cell sites (Figs. 5A, center, and S8C). In 320 contrast, no obvious effects on cell division nor on mid-cell recruitment of ZipA ${ }^{\text {mCherry }}$ 321 and $\mathrm{NIpD}^{\mathrm{mCherry}}$ was observed (Fig. S7A). The overproduction of BamA alone was 322 sufficient to alter the distribution of the DoIP ${ }^{G F P}$ fluorescence signal in constricting cells, reducing its intensity at constriction sites and enhancing it at decentred

324 positions along the cell axis (Fig. 5B, right plot). In contrast, the overproduction of only the four BAM lipoproteins (Fig. 5A, right) as well as the overproduction of OmpA (Fig. S7B) had no obvious effects on DolP mid-cell localization.

As BAM catalyzes OMP assembly, we asked whether this activity interferes

328 with DolP mid-cell localization. To address this question, we made use of an 329 inactive BamA mutant form (Fig. S8A) harbouring a polyhistidine peptide extension 330 at its $\mathrm{C}$-terminal $\beta$-strand ${ }^{57}$. Similar to the overaccumulation of the BAM complex or 
331 BamA, the overaccumulation of BamA ${ }^{\text {His }}$ interfered with DolP mid-cell localization

332 (Figs. S8B and S8C), without affecting ZipA ${ }^{\text {mCherry }}$ and NIpD ${ }^{\text {mCherry }}$ (Fig. S7C),

333 indicating that the cellular localization of DolP does not depend on the OMP334 assembly activity of BamA. In contrast, the ability of BamA to assemble into the OM 335 was a critical determinant of the observed septal depletion of DolP. In fact, the 336 periplasm-accumulating BamA $^{\Delta \mathrm{P} 1 / \mathrm{His}}$ variant (Fig. S8D) did not impair DolP ${ }^{\mathrm{GFP}}$ mid337 cell localization (Fig. S8B, center), whereas the OM-overaccumulating BamA ${ }^{\Delta \mathrm{P} 2 / \mathrm{His}}$ 338 did (Figs. S8B, right, S8C, and S8D). Taken together, these results suggest that the overaccumulation of BamA in the OM interferes with the recruitment of DolP at midcell sites.

DolP mid-cell localization is impaired under envelope stress conditions

As DolP is critical for fitness under envelope stress conditions, we asked

344 whether the localization of DolP ${ }^{\text {GFP }}$ would be affected in mutants undergoing envelope stress. To this end, we analyzed the localization of DolPGFP in strains lacking either the OMP chaperone SurA or the lipoprotein BamB. Both $\Delta s u r A$ and $\triangle$ bamB strains are defective in OMP biogenesis and produce higher levels of BAM complex due to activation of the $\sigma^{\mathrm{E}}$ response ${ }^{19,51,52,58}$. Importantly, the frequency of mid-cell labelling by DolP ${ }^{\text {GFP }}$ was reduced in $\triangle$ surA cells both in minimal (Fig. S9A) and LB (Fig. 5C) culture media. In contrast, lack of SurA did not affect septal recruitment of the late cell division marker NIpD (Fig. S9B). The analysis of the fluorescence plot profiles of constricted cells clearly showed a marked reduction of the DolP ${ }^{G F P}$ signal at mid-cell sites and higher fluorescence levels in decentred positions along the cell axis (Fig. $5 \mathrm{C}$, right plot). As for the $\Delta$ surA strain, DolP ${ }^{\mathrm{GFP}}$ accumulated at the mid-cell with a lower frequency when bamB was deleted (Fig. $\mathrm{S} 9 \mathrm{C})$. Together, these results indicate that the depletion of DolP at mid-cell sites occurs during envelope stress-induced activation of the $\sigma^{\mathrm{E}}$ response. 


\section{Discussion}

Despite its critical role in maintaining OM integrity, the reason why DolP is upregulated by $\sigma^{\mathrm{E}}$ has remained unclear ${ }^{32-34}$. Here we demonstrate that DolP

362 interacts with the BAM complex and is crucial for fitness in cells with elevated $\sigma^{\mathrm{E}}$ 363 activity and when BAM overaccumulates in the OM. Our results have important 364 implications for the understanding of the mechanisms that coordinate OM and peptidoglycan remodelling and help preserving envelope integrity.

A previous study ${ }^{34}$ has shown that the concomitant deletion of dolP and surA generates a severe synthetic growth defect. However, the role of DolP during envelope stress and in OMP biogenesis had remained unclear ${ }^{34,36}$. Here we demonstrate that DolP interacts with the BamA subunits of the BAM complex. DolP, however, is not a stoichiometric component of the BAM complex and thus this interaction is probably transient or has a lower affinity compared to the interactions between BamA and the lipoproteins of the BAM complex. Several pieces of evidence presented in this study suggest that DoIP is not strictly required for OMP assembly into the OM. In addition, we show that the deletion of dolP does not cause envelope stress and activation of the $\sigma^{\mathrm{E}}$ response. Increased $\sigma^{\mathrm{E}}$ activity has been reported to alleviate growth defects caused by the absence or inactivation of OMP biogenesis factors ${ }^{59-62}$. On the contrary, activation of $\sigma^{\mathrm{E}}$ caused a growth defect in a $\Delta d o l P$ strain. This result suggests that, under envelope stress conditions, DolP plays a fitness role that is not directly related to OMP biogenesis. More specifically, we have obtained evidence that DolP opposes a detrimental effect that can derive from the overaccumulation of BAM complex in the OM.

Further studies are warranted to determine the molecular bases of how DolP 383 promotes fitness during activation of the $\sigma^{\mathrm{E}}$ response. It is worth noting, however, 384 that DolP consists of two BON (bacterial OsmY and nodulation) domains, folding 385 motifs that have been proposed to interact with hydrophobic ligands such as lipids $386{ }^{63}$. Phospholipid-binding by DolP has been reported in a recent study ${ }^{64}$. A key 
aspect of our results hints at a possible role of the lipid-binding function of DolP in improving the fitness of cells that undergo envelope stress. We have shown that DolP interacts with OM-assembled BamA, a subunit of the BAM complex that is predicted to interfere with the organization of the surrounding lipid bilayer and to generate an energetically favourable environment for the insertion of nascent OMPs in the $\mathrm{OM}^{65,66}$. BamA-mediated membrane destabilization was shown by molecular dynamics simulations, as well as by reconstituting BamA into proteoliposomes ${ }^{9,67}$.

394 Here, we have provided evidence that the progressive overaccumulation of BAM in the OM has an increasingly detrimental effect, enhancing the OM permeability at low increments and impairing growth at higher levels. Our observation that DolP is needed for optimal growth when the BAM complex overaccumulates in the $\mathrm{OM}$ is compatible with a role of DolP in membrane stabilization at BAM sites. It remains to be seen how DolP docks to BamA and whether it influences the organization of BAM sites and of the surrounding lipid bilayer.

Another key finding of our study is that DolP septal localization is sensitive to envelope stress conditions. During envelope stress, the OM undergoes a significant alteration of its protein composition. Activation of the $\sigma^{\mathrm{E}}$ response triggers activation

404 of genes encoding OMP biogenesis factors, but also the posttranscriptional downregulation of many OMPs including porins and OmpA ${ }^{25}$. OMPs are largely arranged in clusters ${ }^{68-70}$ embedded by highly organized LPS molecules in the external leaflet of the $\mathrm{OM}^{4}$ and the rigidity of their $\beta$-barrel structures contributes to

408 the mechanical stiffness of the $\mathrm{OM}^{71}$. Posttranscriptional downregulation targets of $409 \sigma^{\mathrm{E}}$ activation also include the lipoproteins Pal and Lpp ${ }^{53,54}$, which are critical for OM 410 integrity ${ }^{72,73}$. Whereas we have shown that BAM overaccumulation in the OM 411 influences DolP localization, it is possible that other modifications of the OM during 412 envelope stress contribute to impair the recruitment of DolP at constriction sites.

413 Distinct biogenesis and surveillance pathways are required to maintain the 414 protective function of the multi-layered envelope of Gram-negative bacteria ${ }^{2}$. Our 
415 CRISPRi analysis shows that DolP promotes efficient cell growth when the AmiA

416 pathway of septal peptidoglycan splitting is impaired. This result is in line with the

417 conclusions of a previous study implicating DolP in the regulation of NIpD-mediated

418 activation of $\mathrm{AmiC}^{33}$. Cells lacking both $\mathrm{NIpD}$ and $\mathrm{AmiC}$ have reduced OM integrity

41933 , which may contribute to explain the vancomycin sensitivity of $\Delta d o l P$ cells. It

420 remains poorly understood whether envelope stress caused by the accumulation of

421 unfolded OMPs influences peptidoglycan remodelling. Intriguingly, our observation

422 that mid-cell localization of DolP is reduced in surA and bamB deletion strains

423 points to a possible role of DolP in linking envelope stress to septal peptidoglycan

424 hydrolysis. Reduced levels of DolP at mid-cell sites, and thus impaired AmiC 425 activation ${ }^{33}$, could play an important role in coping with envelope stress, for 426 instance by regulating the window of time available to restore normal OMP

427 biogenesis prior to completing the formation of the new poles in the cell offspring.

428 Taken together, our results reveal an unprecedented link between activation 429 of the envelope stress response and a late step of cell division. The fitness role of

430 DolP during envelope stress emerges as an exploitable target in the development of 431 new antibacterial therapies. 
Materials and Methods

\section{Bacterial strains and growth conditions}

All E. coli strains used in this study are listed in Table S3. Strains newly generated for this study derive from BW25113 $[\Delta(\operatorname{araD}$-araB $) 567 \Delta(r h a D$-rhaB $) 568$ SlacZ4787 (::rrnB-3) hsdR514 rph-1] ${ }^{74}$ or MG1655 $\left(\mathrm{F}^{-} \lambda^{-}\right.$ilvG ${ }^{-}$rfb-50 rph-1) ${ }^{75}$.

438 Deletions of $\operatorname{dol} P, \operatorname{rse} A$, surA, bamB, $\operatorname{deg} P$, or skp in a BW25113 strain were achieved by $\mathrm{P} 1$ transduction of the $\Delta d o l P:: k a n^{R}, \Delta r s e A:: k a n^{R}, \Delta s u r A:: k a n^{R}$, $\Delta$ bamB::kan ${ }^{R}, \Delta d e g P:: k a n^{R}$ or $\Delta s k p:: k a n^{R}$ alleles, respectively, obtained from the corresponding Keio collection strains ${ }^{37}$. BW25113 derivative strains harbouring chromosomal fusions of constructs encoding superfolder GFP downstream of dolP or mCherry downstream of $n / p D$, zipA and bamD were obtained by $\lambda$-red recombination as previously described ${ }^{76}$. Briefly, a kanamycin-resistance cassette was amplified from plasmid pKD4 using oligonucleotides carrying extensions of approximately 50 nucleotides homologous to regions immediately upstream or downstream the stop codon of the interested genes. Dpnl-digested and purified PCR products were electroporated into the BW25113 or derivative strains. Recombinant clones were selected at $37^{\circ} \mathrm{C}$ on LB agar plates containing kanamycin. When necessary, the $\operatorname{kan}^{R}$ cassette inserted into a mutated locus (gene deletion or fusion) was removed upon transformation with the heat-curable plasmid pCP20 ${ }^{76}$. The MG1655 derivative strain LC-E75, harbouring a dCas9-encoding construct under the control of the $\mathrm{P}_{\text {tet }}$ promoter, has been described ${ }^{38}$. Cells were cultured in home-made lysogeny broth (LB) medium (1\% (w/v) tryptone, $0.5 \%(\mathrm{w} / \mathrm{v})$ yeast extract, $5 \mathrm{mg} / \mathrm{ml}$ (NaCl), commercially available Miller LB Broth (Sigma) or M9 minimal medium containing $\mathrm{M} 9$ salts $\left(33.7 \mathrm{mM} \mathrm{Na}_{2} \mathrm{HPO}_{4}, 22 \mathrm{mM} \mathrm{KH} \mathrm{PO}_{4}, 8.55 \mathrm{mM}\right.$ $\mathrm{NaCl}, 9.35 \mathrm{mM} \mathrm{NH}_{4} \mathrm{Cl}$ ) and supplemented with $0.2 \% \mathrm{w} / \mathrm{v}$ glycerol and all the amino

458 acids, or all amino acids except methionine and cysteine in the case of ${ }^{35} \mathrm{~S}$ pulse459 chase labeling. Antibiotics were used at the following concentrations: ampicillin 100 $460 \mu \mathrm{g} / \mathrm{ml}$, kanamycin $50 \mu \mathrm{g} / \mathrm{ml}$, vancomycin $60 \mu \mathrm{g} / \mathrm{ml}$. For spot tests, cells were 
cultured to mid-log phase, washed with M9 salts and serially diluted in ice-cold M9 salts prior to spotting on agar plates.

\section{Plasmid construction}

All plasmids used in data figures are listed in Table S4. Plasmids for the ectopic expression of BAM subunits, DolP, or OmpA are derived from a pTrc99a vector. The plasmid $\mathrm{pBAM}^{\mathrm{His}}$ (pJH114), which harbours a $\mathrm{P}_{\text {trc }}$ promoter followed by the bamABCDE open reading frames and an octahistidine tag fused downstream of bamE, was described ${ }^{55}$. The region of pBAM $^{\text {His }}$ comprising the segment that spans from the bamA start codon to the bamE stop codon was deleted by site-directed mutagenesis, generating pCtrl. Plasmids $\mathrm{pBamA}^{\mathrm{His}}$ was generated by restrictionfree cloning, inserting the bamA ORF without its stop codon downstream of the $\mathrm{P}_{\text {trc }}$ promoter and upstream of the octahistidine encoding region in pCtrl. pBamA ${ }^{\text {His }}$ was subjected to site directed mutagenesis to generate pBamA, encoding wild-type, non-tagged BamA. The dolP ORF amplified from the BW25113 genomic DNA was used to replace the bamABCDE ORFs in pJH114 by restriction-free cloning,

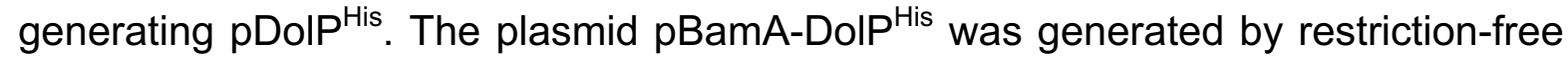

478 cloning of the bamA ORF between the $\mathrm{P}_{\text {trc }}$ promoter and dolP in pDolP $\mathrm{P}^{\mathrm{His}}$. Site479 directed mutagenesis was conducted on $\operatorname{pBAM}^{\mathrm{His}}$ (pJH114) to obtain $480 \mathrm{pBamACDE}^{\mathrm{His}}, \mathrm{pBamABDE}^{\mathrm{His}}, \mathrm{pBamBCDE}^{\mathrm{His}}, \mathrm{pBamCDE}^{\mathrm{His}}$. A sequence encoding 481 the tobacco etch virus protease cleavage site (TEV site) followed by a tandem 482 Protein-A tag was amplified from pYM10 ${ }^{77}$ and fused by restriction-free cloning with 483 the last codon of the bamE gene in $\mathrm{pBAM}^{\text {His }}$ to generate $\mathrm{pBAM}^{\text {ProtA }}$. A stop codon 484 was introduced downstream of the bamE last codon to generate pBAM. Plasmids 485 encoding the $\Delta \mathrm{P} 1$ and $\Delta \mathrm{P} 2$ BamA variant were obtained by site-directed mutagenesis deleting the portion of bamA ORFs corresponding to residues E22-

487 K89 or P92-G172, respectively. The TEV site and the tandem Protein-A construct 488 amplified from pYM10 were inserted by restriction-free cloning downstream of the 
489 dolP last codon in $\mathrm{pDolP}^{\mathrm{His}}$, generating $\mathrm{pDolP} \mathrm{P}^{\mathrm{Prot} A}$. pDolP was derived from

490 pDolP ${ }^{\text {ProtA }}$ using site-directed mutagenesis to introduce a stop codon immediately

491 downstream of the dolP ORF. The ompA ORF was amplified from the BW25113

492 genomic DNA and inserted by restriction-free cloning between $P_{\text {trc }}$ and the His-tag

493 encoding construct of $\mathrm{pCtrl}$ to generate $\mathrm{pOmpA}^{\text {His }}$. The sgRNAs plasmids are

494 derived from psgRNAcos ${ }^{38}$. To generate sgRNA-encoding plasmids the DNA

495 sequences AGCTGCACCTGCTGCGAATA (bamD sgRNA, plasmid pCAT187),

496 GTAAACCACTCGCTCCAGAG (bamE sgRNA, plasmid pCAT189),

497 CTCATCCGCGTGGGCGGAAA (envC sgRNA, plasmid pCAT191), and

498 CTGAGCCGCCGACCGATTTA (ftsX sgRNA, pCAT193) were inserted into a Bsal

499 site of the psgRNAcos.

\section{CRISPRi screen and data analysis}

Strain LC-E75 $\left(\right.$ dol $\left.P^{+}\right)$and its $\Delta$ doIP derivative were transformed with the

503 EcoWG1 library which contains 5 guides per gene as previously described ${ }^{39}$. After

504 culturing pooled transformant cells in LB at $37^{\circ} \mathrm{C}$ to early exponential phase (optical density at $600 \mathrm{~nm}\left[\mathrm{OD}_{600}\right]=0.2$ ), a sample was withdrawn for plasmid isolation

506 ( $\left.\mathrm{t}_{\text {start }}\right)$. Subsequently, cultures were supplemented with $1 \mu \mathrm{M}$ anhydrotetracycline

507 (aTc) to induce dCas9 expression and further incubated at $37^{\circ} \mathrm{C}$. When cultures 508 reached an $\mathrm{OD}_{600}$ of 2 they were diluted 1:100 into LB supplemented with $1 \mu \mathrm{M}$ aTc

509 and incubated at the same temperature until an $\mathrm{OD}_{600}$ of 2 . This step was repeated 510 one more time prior to withdrawing a sample for isolation of plasmid DNA (tend). 511 Sequencing indexes were used to assign reads to each sample. Illumina

512 sequencing samples were prepared and analyzed as previously described ${ }^{38}$.

513 Briefly, a two-step PCR was performed with Phusion polymerase (Thermo

514 Scientific) using indexed primers. The first PCR adds the first index and the second

515 PCR adds the second index and flow-cell attachment sequences. Pooled PCR 516 products were gel-purified. Sequencing was performed on a NextSeq550 machine 
517 (Illumina). The total number of reads obtained for each sample was used to

518 normalize raw reads by sample size. Replicates were pooled to increase depth

519 before another normalization by sample size. Guides with less than 100 normalized 520 read counts in initial time points were discarded. For each screen, sgRNA fitness

521 was calculated as the log2-transformed ratio of normalized reads counts between

522 the final and the initial time point:

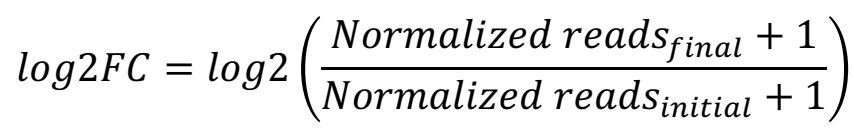

524 For each sample, log2FC values were centered by subtracting the median log2FC of non-targeting control guides. We then calculated for each sgRNA the difference

526 of log2FC value between the $\Delta$ doIP screen and the dolP ${ }^{+}$screen. Guides were

527 ranked from the lowest negative values (negative fitness effect in $\Delta$ dolP compared 528 to $d o l P^{+}$) to the highest positive values (positive fitness effect in $\Delta d o l P$ compared to $529 d o / P^{+}$) and the significance of the interaction between dolP and each gene was 530 evaluated by performing a minimum hypergeometric $(\mathrm{mHG})$ test on the ranked list 531 for each gene using the $\mathrm{mHG}$ R package (v. 1.1) ${ }^{78}$. False-discovery rate (FDR) was 532 used to correct $p$-values for multiple testing. For each gene, the median difference 533 of log2FC between $\Delta d o l P$ and $d o / P^{+}$screens was used as a measure of the genetic 534 interaction.

\section{Cell fractionation}

To prepare whole-cell lysates, cells were cultured to early exponential phase

$538\left(\mathrm{OD}_{600}=0.2-0.3\right)$ in $\mathrm{LB}$ medium at $37^{\circ} \mathrm{C}$ and collected. Where indicated, IPTG was 539 added 60 min prior to cell collection. Cells were pelleted by centrifugation, washed 540 once with M9 salt and lysed with Laemmli Sample Buffer (BioRad) (69 mM Tris-HCl, $541 \mathrm{pH} 6.8,11.1 \%[\mathrm{v} / \mathrm{v}]$ glycerol, $1.1 \%$ [w/v] lithium dodecyl sulfate [LDS], 0.005\% [w/v] 542 bromophenol blue, supplemented with $357 \mathrm{mM} \beta$-mercaptoethanol and $2 \mathrm{mM}$ 
543 phenylmethylsulfonyl fluoride [PMSF]). The total protein content was denatured at

$54498^{\circ} \mathrm{C}$ for 5 min prior SDS-PAGE analysis.

545 To perform lysozyme/EDTA lysis, cells were cultured to early exponential phase, 546 collected by centrifugation, resuspended in $33 \mathrm{mM}$ Tris- $\mathrm{HCl} \mathrm{pH} 8$ to an $\mathrm{OD}_{600}$ of 1.

547 The cell suspension was then supplemented with $0.1 \mathrm{mg} / \mathrm{ml}$ lysozyme (Sigma), 2 $548 \mathrm{mM}$ EDTA and incubated on ice for 20 minutes to induce lysis. After addition of 10 $\mathrm{mM} \mathrm{MgSO}_{4}$, the membrane fraction was collected by centrifugation at 16000x $\mathrm{g}$. The

550 supernatant was further centrifuged at $100000 \times \mathrm{x}$ to remove any residual membrane fraction, which was discarded. The obtained soluble fraction was subjected to protein precipitation by adding $10 \%(\mathrm{w} / \mathrm{v})$ trichloroacetic acid (TCA). TCA precipitates were solubilized in Laemmli Sample Buffer (BioRad) prior to SDSPAGE analysis.

The crude envelope fractions directly analyzes by SDS-PAGE or used for native affinity purification of affinity tagged BAM complex or DolP were prepared from cells that were cultured in LB until early exponential phase and, where

558 indicated, supplemented with $400 \mu \mathrm{M}$ IPTG for 1 hour to induce ectopic expression.

559 Cells were collected by centrifugation at $6000 \times \mathrm{g}$ at $4^{\circ} \mathrm{C}$, resuspended in $20 \mathrm{mM}$ 560 Tris- $\mathrm{HCl} \mathrm{pH} \mathrm{8,} \mathrm{and} \mathrm{mechanically} \mathrm{disrupted} \mathrm{using} \mathrm{a} \mathrm{Cell} \mathrm{Disruptor} \mathrm{(Constant}$ 561 Systems LTD) set to $0.82 \mathrm{kPa}$. The obtained cell lysate fractions were clarified by centrifugation at $6000 \mathrm{x} g$ and $4^{\circ} \mathrm{C}$. The supernatant was then subjected to ultracentrifugation at $100000 \mathrm{x} g$ at $4^{\circ} \mathrm{C}$ to collect the envelope fraction.

565 Isolation of native protein complexes by IgG- or nickel-affinity 566 chromatography

The envelope fraction was resuspended at a concentration of approximately $56810 \mathrm{mg} / \mathrm{ml}$ in solubilization buffer $(20 \mathrm{mM}$ Tris- $\mathrm{HCl} \mathrm{pH} 7.4,100 \mathrm{mM} \mathrm{NaCl}, 0.1 \mathrm{mM}$ 569 EDTA, 2 mM PMSF) supplemented with EDTA-free protease inhibitor cocktail 
570 (Roche), and 1.1\% (w/v) of a mild detergent component corresponding to digitonin

571 (Merck) and n-dodecyl $\beta$-D-maltoside (DDM, Merck) as indicated in Figure Legends.

572 To facilitate extraction of membrane proteins, samples were subjected to mild 573 agitation for 1 hour at $4^{\circ} \mathrm{C}$. Insoluble material was removed by centrifugation at $57416000 \times g$ at $4^{\circ} \mathrm{C}$. To perform IgG affinity purification, membrane-extracted proteins 575 were incubated for 1.5 hours at $4^{\circ} \mathrm{C}$ with purified human IgG (Sigma) that had been 576 previously coupled to CNBr-activated Sepharose beads (GE Healthcare). After 577 extensive washes of the resin with solubilization buffer containing $0.3 \%(\mathrm{w} / \mathrm{v})$ 578 digitonin and $0.03 \%(w / v)$ DDM, bound proteins were eluted by incubation with 579 AcTEV protease (ThermoFisher) overnight at $4^{\circ} \mathrm{C}$ under mild agitation. To perform 580 nickel (Ni)-affinity purification, membrane-extracted proteins were supplemented 581 with $20 \mathrm{mM}$ imidazole and incubated with Protino Ni-NTA agarose beads 582 (Macherey-Nagel) for 1 hour at $4^{\circ} \mathrm{C}$. After extensive washes of the resin with solubilization buffer supplemented with $50 \mathrm{mM}$ imidazole, $0.3 \%$ (w/v) digitonin, $0.03 \%(w / v)$ DDM, and the EDTA-free protease inhibitor cocktail (Roche), bound proteins were eluted using the same buffer supplemented with $500 \mathrm{mM}$ imidazole.

\section{In vitro reconstitution of the BAM-DolP interaction and BN-PAGE analysis}

Envelope fractions were obtained from cells carrying $\mathrm{pBAM}^{\mathrm{His}}$ or $\mathrm{pDolP} \mathrm{P}^{\mathrm{His}}$ and cultured until early exponential phase in LB medium at $37^{\circ} \mathrm{C}$ and subsequently supplemented with $400 \mu \mathrm{M}$ IPTG for 1.5 hours to induce the expression of the BAM complex genes or dolP. The envelope fractions were solubilized and purified by Niaffinity and size exclusion chromatography, adapting a previously published

593 protocol. Briefly, after membrane solubilization with $50 \mathrm{mM}$ Tris- $\mathrm{HCl} \mathrm{pH} 8.0,150$

$594 \mathrm{mM} \mathrm{NaCl}$, and $1 \%(\mathrm{w} / \mathrm{v}) \mathrm{DDM}$, and removal of insoluble material by ultracentrifugation at $100000 \times \mathrm{g}, 4^{\circ} \mathrm{C}$, soluble proteins were loaded onto a $\mathrm{Ni}$ -

596 column (HisTrap FF Crude, GE Healthcare) pre-equilibrated with $50 \mathrm{mM}$ Tris- $\mathrm{HCl}$

$597 \mathrm{pH}$ 8.0, $150 \mathrm{mM} \mathrm{NaCl}$, and 0.03\% (w/v) DDM (equilibration buffer), using an ÄKTA 
598 Purifier 10 (GE Healthcare) at $4^{\circ} \mathrm{C}$. The column containing bound proteins was

599 washed with equilibration buffer supplemented with $50 \mathrm{mM}$ imidazole. Proteins were

600 eluted in equilibration buffer, applying a gradient of imidazole from $50 \mathrm{mM}$ to 500

$601 \mathrm{mM}$ and further separated by gel filtration using an HiLoad 16/600 Superdex 200

602 (GE Healthcare) in equilibration buffer. Eluted proteins were concentrated using an

603 ultrafiltration membrane with a $10 \mathrm{kDa}$ molecular weight cutoff (Vivaspin 6,

604 Sartorius). To reconstitute the BAM-DolP complex in vitro, equimolar concentrations

605 of purified BAM and DolP were used. Purified proteins were mixed in equilibration

606 buffer for 1 hour at $4^{\circ} \mathrm{C}$ or for $30 \mathrm{~min}$ at $25^{\circ} \mathrm{C}$ as indicated in Figure Legends. The

607 reaction was further diluted 1:4 times in ice-cold blue native buffer $(20 \mathrm{mM}$ Tris- $\mathrm{HCl}$

$608 \mathrm{pH} 7.4,50 \mathrm{mM} \mathrm{NaCl}, 0.1 \mathrm{mM}$ EDTA, 1\% [w/v] digitonin, 10\% w/v glycerol) and ice

609 cold blue native loading buffer (5\% coomassie brilliant blue G-250, 100 mM Bis-

610 Tris- $\mathrm{HCl}, \mathrm{pH} 7.0,500 \mathrm{mM} \mathrm{6-aminocaproic} \mathrm{acid)} \mathrm{prior} \mathrm{to} \mathrm{loading} \mathrm{onto} \mathrm{home-made} \mathrm{5-}$

611 13\% blue native polyacrylamide gradient gels. Resolved protein complexes were

612 blotted onto a PVDF membrane and immunolabeled. Where non-relevant gel lanes

613 were removed, a white space was used to separate contiguous parts of the same

614 gel.

615

616 Pulse-chase in vivo protein labeling

617 Pulse-chase labeling of cellular proteins with radioactive ${ }^{35} \mathrm{~S}$ methionine and

618 cysteine was conducted as previously described ${ }^{79}$. Briefly, overnight cultures were

619 washed and freshly diluted into $M 9$ medium to $\mathrm{OD}_{600}=0.03$ and incubated at $37^{\circ} \mathrm{C}$.

620 When the cultures reached $\mathrm{OD}_{600}=0.3$, ectopic expression of EspP was induced by

621 adding $200 \mu \mathrm{M}$ IPTG for $30 \mathrm{~min} .{ }^{35} \mathrm{~S}$ labelling was performed by supplementing

622 cultures with a mixture of $\left[{ }^{35} \mathrm{~S}\right]$-methionine and $\left[{ }^{35} \mathrm{~S}\right]$-cysteine followed after 30

623 seconds by the addition of an excess of cold methionine and cysteine. Samples

624 were withdrawn at different chase times, immediately mixed with an equal volume of

625 ice and subjected to TCA precipitation, prior to immunoprecipitation. 


\section{Antibodies}

Proteins separated by SDS-PAGE or blue native-PAGE and blotted onto PVDF membranes were immunodecorated using epitope-specific rabbit polyclonal antisera with the following exceptions. The $F_{1} \beta$ subunit of the ATP $F_{1} F_{O}$ synthase was detected using a rabbit polyclonal antiserum raised against an epitope of the

632 homologous protein of Saccharomyces cerevisiae (Atp2). RpoB was detected using 633 a mouse monoclonal antibody (NeoClone Biotechnology). The secondary 634 immunodecoration was conducted using anti-rabbit or anti-mouse peroxidase635 conjugated antibodies produced in goat (Sigma). EspP immunoprecipitation was 636 conducted using a rabbit polyclonal antiserum specific for a C-terminal epitope of 637 EspP.

\section{Epifluorescence microscopy and analysis}

Overnight cultures of E. coli BW25113 and its derivative strains were diluted

641 into fresh M9 medium containing $0.2 \%$ glycerol or LB medium and grown at $30^{\circ} \mathrm{C}$ to $642 \mathrm{OD}_{600}=0.2-0.3$. When indicated, cultures were supplemented with $400 \mu \mathrm{M}$ of IPTG 643 to induce ectopic expression of plasmid-borne genes for 1 hour prior to collecting 644 samples for microscopy analysis. Culture volumes of $0.6 \mu$ l were deposited directly 645 onto slides coated with $1 \%(\mathrm{w} / \mathrm{v})$ agarose in a phosphate-buffered saline solution 646 and visualized by epifluorescence microscopy. Cells were imaged at $30^{\circ} \mathrm{C}$ using an 647 Eclipse TI-E/B Nikon wide field epifluorescence inverted microscope with a phase 648 contrast objective (Plan APO LBDA 100X oil NA1.4 Phase) and a Semrock filter 649 mCherry (Ex: 562BP24; DM: 593; Em: 641BP75) or FITC (Ex: 482BP35; DM: 506; 650 Em: 536BP40). Images were acquired using a CDD OrcaR2 (Hamamatsu) camera 651 with illumination at $100 \%$ from a HG Intensilight source and with an exposure time 652 of $1-3$ seconds, or using a Neo 5.5 sCMOS (Andor) camera with illumination at $60 \%$ 
653 from a LED SPECTRA $X$ source (Lumencor) with an exposure time of 2 seconds.

654 Nis-Elements AR software (Nikon) was used for image capture. Image analysis was 655 conducted using the Fiji and ImageJ software. The fraction of cells with DoIPGPF 656 signals at mid-cell sites was estimated using the Fiji Cell Counter plugin. Collective 657 profiles of fluorescence distribution versus the relative position along the cell axis were generated using the Coli-Inspector macro run in ImageJ within the plugin ObjectJ ${ }^{80}$, selecting only cells with a constriction ( $80 \%$ of cell diameter) as qualified 660 objects.

\section{Acknowledgments}

We thank Harris Bernstein (NIDDK/NIH, Bethesda, MD) for providing key reagents and for comments on the manuscript. We thank Tanneke Den Blaauwen (University of Amsterdam) and Nathalie Dautin (IBPC/CNRS, Paris) for discussion. We thank the Light Imaging Toulouse CBI (LITC) platform for assistance with and maintenance of the microscopy instrumentation. Financial support was provided by: the Fondation pour la Recherche Médicale to D.R.; the Chinese Scholarship

669 Council to Y.Y.; the Ecole Normale Supérieure to F.R.; the European Research

670 Council (Europe Union's Horizon 2020 research and innovation program, grant 671 agreement No 677823), the French governmental Investissement d'Avenir program 672 and the Laboratoire d'Excellence "Integrative Biology of Emerging Infectious 673 Diseases" (ANR-10-LABX-62-IBEID) to D.B.; the CNRS ATIP-Avenir program to 674 R.I.

\section{Author contribution}

R.I. conceived the project and wrote the manuscript; D.B. conceived and

678 developed the CRISPRi approach; R.I., D.B., D.R. L.C. and C.A. supervised the 
679 experiments; D.R., Y.Y., L.O., F.R., L.C., V.M., C.M., G.M., A.C.-S, C.T., J.R. and 680 C.A. performed the experiments and analyzed the data together with R.I. and D.B.; 681 A.C.-S, D.R., Y.Y., L.O. and F.R. prepared the figures; all authors discussed the 682 project and the experimental results, and commented on the manuscript. 
Fig. 1. Genome-wide screen of dolP interactions.

687 (A) The deletion of dolP impairs OM integrity. The indicated strains were serially 688 diluted and spotted onto LB agar plates lacking or supplemented with $60 \mu \mathrm{g} / \mathrm{ml}$ vancomycin as indicated.

690 (B) Schematic representation of the CRISPR-based gene silencing approach. LC$691 \mathrm{E} 75\left(\right.$ dol $\left.P^{+}\right)$or its $\Delta$ dolP derivative strain, both carrying dcas 9 under the control of 692 an anhydrotetracycline (aTc)-inducible promoter in their chromosome were 693 transformed with a library of plasmids encoding gene-specific sgRNAs. The library 694 covers any E. coli MG1655 genetic features with an average of 5 sgRNAs per gene.

695 Pooled transformed cells were cultured to early exponential phase prior to plasmid 696 extraction and quantitative Illumina sequencing to assess the initial distribution of 697 sgRNA constructs in each culture ( $\left.\mathrm{t}_{\text {start }}\right)$. Upon addition of $1 \mu \mathrm{M}$ aTc to induce 698 sgRNA-mediated targeting of dcas 9 for approximately 17 generations, samples of 699 cells from each culture were newly subjected to plasmid extraction and Illumina sequencing to determine the final distribution of sgRNA constructs $\left(t_{\text {end }}\right)$.

701 (C) Left: Comparison of gene scores obtained in dolP $P^{+}$and $\Delta d o l P$ screens. The log2 702 fold-change (log2FC) between $t_{\text {end }}$ and $t_{\text {start }}$ calculated for each sgRNAs (Fig. S2B) was grouped by gene target, and their median (Table S1) was used to derive fitness gene scores. Right: Volcano plot of the dolP genetic interaction (GI) scores. The xaxis shows a genetic interaction score calculated for each gene based on the minimum hypergeometric $(\mathrm{mHG})$ test conducted on the ranked difference of sgRNA-specific log2FC values between the $\Delta d o I P$ and the dolP ${ }^{+}$screens. The $y-$ axis shows the log10 of the false discovery rate (FDR) of the test. The dashed line shows FDR $=0.05$. In both panels, genes highlighted in orange have FDR $<0.05$ and $\mathrm{Gl}>1$ whereas genes highlighted in red have $\mathrm{FDR}<0.05$ and $\mathrm{Gl}>2$. 
711 (D and E) Validation of the genetic interactions determined in (C). (D) LC-E75

$712\left(\right.$ dol $\left.P^{+}\right)$or its $\Delta$ dolP derivative strain expressing sgRNAs that target the indicated

713 genes were serially diluted and spotted on LB agar lacking or supplemented with

714 aTc to induce expression of dcas9, as indicated. (E) BW25113 derivative cells

715 deleted of $r s e A$ or both $r s e A$ and dolP were transformed with an empty vector 716 (pCtrl) or a plasmid encoding DolP (pDolP ${ }^{H i s}$ ). Ectopic expression of DolP ${ }^{\text {His }}$ was

717 driven by the leaky transcriptional activity of $P_{\text {trc }}$ in the absence of IPTG. (D and E)

718 10-fold serial dilutions of the indicated transformants were spotted on LB agar.

720 Fig. 2. DolP promotes fitness in cells that undergo envelope stress.

721 (A) One and three folds of a sample containing the total cell lysate fraction from a 722 BW25113 $\left(\right.$ dol $\left.P^{+}\right)$strain and a derivative $\Delta$ dolP strain were analyzed by SDS-PAGE 723 and immunoblotting using the indicated antisera.

724 (B) One, two and three folds of a sample containing the total cell lysate fraction from 725 a BW25113 (bamB $\left.{ }^{+}\right)$strain and a derivative $\triangle$ bamB strain were analyzed by SDS726 PAGE and immunoblotting using the indicated antisera.

727 (C) BW25113 and derivative cells deleted of dolP, bamB or both genes were 728 cultured, serially diluted and spotted on LB agar. A BW25113 derivative strain 729 deleted of both dolP and bamB and transformed with pDolP $P^{\text {His }}$ was cultured, serially 730 diluted and spotted on LB agar supplemented with ampicillin.

731 (D) Overnight cultures of BW25113 (control), $\Delta d o l P, \Delta$ bamB and $\Delta$ dolP $\Delta$ bamB, 732 were freshly diluted in LB medium and re-incubated at $30^{\circ} \mathrm{C}$ until $\mathrm{OD}_{600}=0.3$. Cell 733 were visualized on $1 \%(\mathrm{w} / \mathrm{v})$ agarose pads by phase contrast microscopy. Bar $=5$ $734 \mu \mathrm{m}$. 

overaccumulation.

(A) BW25113 cells harbouring $\mathrm{pBAM}^{\mathrm{His}}$ as indicated were cultured and supplemented with no IPTG or $400 \mu \mathrm{M}$ IPTG for 1 hour prior to collecting cells. The protein contents of the envelope fractions were analysed by SDS-PAGE and coomassie staining. Prior to loading, samples were heated for $5 \mathrm{~min}$ at $90^{\circ} \mathrm{C}$, a

743 temperature which is not sufficient to fully denature OmpA (folded OmpA, fOmpA).

744 The band of BamB overlaps with the band of the major porin unfolded OmpC 745 (uOmpC).

746 (B) BW25113 cells carrying a control empty vector ( $\mathrm{pCtrl}$ ), or the indicated plasmids 747 for ectopic overproduction of BAM or subsets of BAM subunits or OmpA were serially diluted and spotted on LB agar containing $400 \mu \mathrm{M}$ IPTG. The diagrams show the overproduces proteins.

(C) Wild-type BW25113 cells carrying an empty control vector (pCtrl) or pBAM $^{\text {His }}$ were serially diluted and spotted on LB agar lacking or supplemented with $60 \mu \mathrm{g} / \mathrm{ml}$ vancomycin. No IPTG was added to these medium.

(D) The BW25113 and the derivative $\Delta d o l P$ or $\Delta s k p$ strains carrying an empty control vector $(\mathrm{pCtrl})$ or $\mathrm{pBAM}^{\mathrm{His}}$ were serially diluted and spotted on LB agar supplemented with 400 or $200 \mu \mathrm{M}$ IPTG, as indicated.

Fig. 4. DoIP associates with the BAM complex via an interaction with BamA.

(A, B). The envelope fractions of BW25113 cells carrying the indicated plasmids were solubilized with $1 \%(\mathrm{w} / \mathrm{v})$ digitonin and $0.1 \%(\mathrm{w} / \mathrm{v}) \mathrm{DDM}$ and subjected to IgG

760 affinity purification of either protein A-tagged DolP (A) or protein A-tagged BamE 761 (B). The load and elution fractions were analyzed by SDS-PAGE. The coomassie 762 staining of the elution of protein A-tagged DoIP (A) or protein A-tagged BamE (B) 763 are shown below the diagrams representing overproduced proteins. Blotted protein 
764 from load and elution fractions were detected by immunolabeling using the indicated 765 antisera. Load $0.5 \%$ (A) 1\% (B); Elution 100\%. The asterisk indicates the products 766 of TEV digestion obtained with samples containing $\operatorname{DolP}^{\operatorname{ProtA}}(A)$ or $\operatorname{BamE}^{\operatorname{ProtA}}(B)$.

767 (C) The envelope fractions of BW25113 cells carrying the plasmids overproducing 768 His-tagged DolP and the indicated BamA protein variants (deleted of POTRA1 or of POTRA2) were solubilized with $1 \%(\mathrm{w} / \mathrm{v})$ digitonin and $0.1 \%(\mathrm{w} / \mathrm{v})$ DDM and subjected to Ni-affinity purification. The load and elution fractions were analyzed by SDS-PAGE. The coomassie staining of the elution of His-tagged DolP overproduced together with wild-type BamA is shown below the diagram representing overproduced proteins. Blotted protein from load and elution fractions were detected by immunolabeling using the indicated antisera. Load $2 \%$; Elution $100 \%$.

(D) Equal aliquots of the envelope fraction of BW25113 cells expressing His-tagged DolP were solubilized with the indicated concentrations (w/v) of digitonin and DDM: $1 \%, 0.1 \%$ (lane 1), 0.8\%, 0.3\% (lane 2), 0.3\%, 0.8\% (lane 3), 0.1\%, 1\% (lane 4). His-tagged DolP was purified by Ni-affinity chromatography. In all cases, proteins were eluted in the presence of $0.3 \%(w / v)$ digitonin and $0.03 \%(w / v)$ DDM. Load $0.2 \%$; Elution $100 \%$.

(E) The envelope fraction of BW25113 cells overproducing DolP ${ }^{\text {His }}$ or the BAM complex containing C-terminally His-tagged BamE was subjected to protein extraction with $1 \%(\mathrm{w} / \mathrm{v})$ DDM and Ni-affinity purification and gel filtration chromatographies. The elution fractions were analyzed by SDS-PAGE and coomassie staining. The double asterisk indicates a contaminant protein in the

787 elution of DolP.

788 (F) Roughly equimolar quantities of purified His-tagged BAM complex and DolP were incubated alone for 1 hour at $4^{\circ} \mathrm{C}$ (lanes 1,2 and 7 ), or together for 1 hour at

$7904^{\circ} \mathrm{C}$ (lanes 3 and 6 ) or for 30 min at $25^{\circ} \mathrm{C}$ (lanes 4 and 5), prior to blue native-PAGE 791 and immunoblotting using the indicated antisera. 
Fig. 5. BamA overaccumulation in the $O M$ and envelope stress interfere with mid-cell localization of DolP.

794 (A) Overnight cultures of BW25113 cells harboring the chromosomal fusion dolP795 gfp and transformed with either pCtrl (empty vector) or $\mathrm{pBAM}^{\mathrm{His}}$, or $\mathrm{pBamBCDE}^{\mathrm{His}}$ 796 were freshly diluted in minimal M9 medium, incubated at $30^{\circ} \mathrm{C}$ until $\mathrm{OD}_{600}=0.1$ and 797 supplemented with $400 \mu \mathrm{M}$ IPTG for 1 hour. Cell samples were visualized on $1 \%$ $798(\mathrm{w} / \mathrm{v})$ agarose pads by phase contrast and fluorescence microscopy. Arrowheads 799 indicate envelope constriction sites between forming daughter cells. Bar $=5 \mu \mathrm{m}$.

800 (B) Left: Overnight cultures of BW25113 cells harboring the chromosomal fusion dolP-gfp and transformed with either pCtrl (empty vector) or pBamA were cultured and visualized as in (A). Bar $=5 \mu \mathrm{m}$. Right: The collective profiles of fluorescence distribution versus the relative position along the cell axis were plotted for cells

804 transformed with pBamA (orange) and cells transformed with pCtrl (blue). Only cells with a constriction (187, pBamA; 361, pCtrl) were taken into account for the collective profile plots.

807 (C) Left: Overnight cultures of BW25113 (control) or $\Delta$ surA derivative cells carrying 808 the dolP-gfp chromosomal fusion were freshly diluted in LB medium and incubated

809 at $30^{\circ} \mathrm{C}$ until $\mathrm{OD}_{600}=0.3$. Cell samples were visualized as in $(\mathrm{A})$. Bar $=5 \mu \mathrm{m}$. Right:

810 The collective profiles of fluorescence distribution versus the relative position along

811 the cell axis is shown for $\Delta$ surA cells (orange) and $s u r A^{+}$control cells (blue). Only 812 cells with a constriction (320, $\Delta$ surA; 318 , Control) were taken into account for the 813 collective profile plots.

815 Fig. S1. The deletion of dolP severely impairs growth in the presence of 816 vancomycin.

817 (A) BW25113 and $\triangle$ dolP cells were cultured in LB. The cell densities of both 818 cultures were monitored by measuring the $\mathrm{OD}_{600}$ at regular time intervals. The 
819 graph reports mean values of independent cultures \pm standard deviation $(\mathrm{SD}, n=$ $8203)$.

821 (B) BW25113 (control) and the indicated deletion strains were cultured on LB agar 822 lacking or containing $60 \mu \mathrm{g} / \mathrm{ml}$ vancomycin.

823 (C) BW25113 and $\Delta$ dolP cells carrying the indicated plasmids were serially diluted 824 and spotted on LB lacking or containing $60 \mu \mathrm{g} / \mathrm{ml}$ vancomycin. Ectopic expression 825 was driven by the leaky transcriptional activity of $P_{\text {trc }}$ in the absence of IPTG.

827 Fig. S2. Reproducibility of the CRISPRi screens and ontology analysis of gene 828 hits.

829 (A) The raw read counts of experimental replicates are very well correlated 830 (Pearson's $r>0.97$ ) in both $d o l P^{+}$(left) and $\Delta d o l P$ (right) screens.

831 (B) Log2FC values of each sgRNA are compared between the WT and $\triangle$ doIP 832 screens. Only guides targeting envC, bamD, and $r s e A$ are highlighted in orange, red 833 and cyan, respectively.

834 (C) Gene Ontology analysis of the genes with a significant synthetic interaction with 835 dolP. Using FDR $<0.05$ as a threshold, 27 genes were selected for Gene Ontology 836 (GO) analysis for cellular component (upper panel) or biological process (bottom 837 panel) ${ }^{81}$. Both analyses show an overrepresentation of genes associated with cell 838 envelope and membrane function.

840 Fig. S3. DolP is not crucial for OMP biogenesis.

841 (A) The protein contents of the indicated envelope fractions were analysed by SDS842 PAGE and coomassie staining. Prior to loading, samples were heated at $50^{\circ} \mathrm{C}$ 843 (boiling -) or $99^{\circ} \mathrm{C}$ (boiling + ) for $10 \mathrm{~min}$. 
(B) The protein contents of the envelope fraction of BW25113 (dolP $\left.P^{+}\right)$or $\Delta$ dolP cells were mixed with SDS-PAGE loading buffer, heated at $50^{\circ} \mathrm{C}$ (boiling -) or $99^{\circ} \mathrm{C}$ 846 (boiling +) for $10 \mathrm{~min}$, and analyzed by SDS-PAGE and immunoblotting. Unfolded (u) and folded (f) OmpA forms are indicated.

848 (C and D) The protein contents of the envelope fraction of BW25113 (dol $\left.P^{+}\right)$and $849 \Delta$ dolP cells was mixed with SDS-PAGE loading buffer, heated at the indicated 850 temperatures, separated by SDS-PAGE and immunoblotted using anti-LamB (C) or 851 anti-OmpC (D) antisera. LamB and OmpC form complexes (trimers), which are 852 resistant to SDS and require significant heating to be denatured. At progressively 853 higher temperatures, LamB (C) and OmpC (D) complexes are denatured and the 854 two proteins migrate as monomers (u, unfolded).

855 (E) The biogenesis of EspP, an autotransporter OMP of enterohemorrhagic E. coli 856 heterologously expressed in BW25113 cells, was monitored in time. The plasmid 857 pRI22 ${ }^{79}$ harbouring the EspP encoding gene under the control of an IPTG-inducible promoter was transformed into wild-type BW25113 $\left(d o / P^{+}\right)$and $\Delta d o l P$ cells. EspP is

859 a serine protease autotransporter of Enterobacteriaceae, and consists of an $\mathrm{N}$ 860 terminal passenger domain secreted on the cell surface and a C-terminal domain 861 which is ultimately folded into an integral OM $\beta$-barrel structure ${ }^{82}$. EspP biogenesis 862 requires both periplasmic chaperones, such as SurA, and the BAM complex ${ }^{79}$. 863 Once EspP assembly and secretion are completed, the passenger domain is 864 cleaved by an autocatalytic reaction that is catalyzed by residues of the folded $\beta$ 865 barrel domain facing the interior of the barrel. Thus, the proteolytic reaction can be exploited to infer about completion of $\beta$-barrel folding and assembly ${ }^{82}$. To monitor

867 the kinetics of EspP autoproteolysis, cells carrying pRI22 were cultured in M9 868 minimal medium until early exponential phase, supplemented with $200 \mu \mathrm{M}$ IPTG 869 and subjected to ${ }^{35} \mathrm{~S}$ pulse-chase labelling. The total protein contents of samples 870 collected after the indicated chase times were subjected to immunoprecipitation 871 using an antiserum specific for an EspP C-terminal peptide. The asterisk indicates a 
872 degradation product of EspP, likely generated by the OM protease OmpT, which

873 cleaves the $\mathrm{N}$-terminal region of the passenger domain as it is secreted across the

$874 \mathrm{OM}^{83}$. A band corresponding to the EspP $\beta$-barrel domain is generated with a similar time dependence in both $d o l P^{+}$and $\Delta d o l P$ cells.

876

877 Fig. S4. The detrimental effect of BAM overproduction is caused by the 878 overaccumulation of BAM in the OM

879 (A) BW25113 cells were transformed with an empty vector or vectors for the ectopic expression of the BAM complex containing protein A-tagged BamE $\left(\mathrm{pBAM}^{\mathrm{ProtA}}\right)$, or

881 similar variants of the $B A M$ complex including $B_{a m A}{ }^{\triangle P 1}\left(p B A M^{\triangle P 1 / P r o t A}\right.$, lacking the $882 \mathrm{~N}$-terminal POTRA1 motif) or BamA ${ }^{\triangle \mathrm{P} 2}\left(\mathrm{pBAM}^{\triangle \mathrm{P} 2 / \text { ProtA }}\right.$, lacking the POTRA2 motif) in 883 place of wild-type BamA. In the presence of IPTG, overproduction of $B M^{\triangle P} 1 / P^{2 o t A}$

884 impaired growth to a lower extent compared to overproduction of BAM $^{\text {ProtA }}$ or 885 BAM $^{\triangle P 2 / P r o t A}$.

886 (B) The crude envelope fractions of cells overproducing $B A M^{\text {ProtA }}, B A M^{\triangle P 1 / P r o t A}$, or $887 \mathrm{BAM}^{\triangle \mathrm{P} 2 / \text { ProtA }}$ were solubilized with $1 \%(\mathrm{w} / \mathrm{v})$ digitonin and $0.1 \%(\mathrm{w} / \mathrm{v}) \mathrm{DDM}$, and 888 subjected to native IgG-affinity chromatography. Elutions were analyzed by blue 889 native-PAGE and coomassie staining (lanes 1-3) or SDS-PAGE and immunoblotting 890 (lanes 4-6). Blue native-PAGE of the elution fraction containing wild-type BamA 891 resolved a coomassie stainable complex migrating with an apparent mass of 250 $892 \mathrm{kDa}$, which corresponds to the BAM complex (lane 1). A roughly similar amount of 893 BAM complex was detected in the elution obtained with BamA $A^{\triangle P 2 / P r o t A}$ samples, 894 although in this case the $\mathrm{BAM}^{\triangle \mathrm{P} 2}$ complex migrated slightly faster, accounting for 895 the $B a m A^{\triangle P 2}$ mass difference (lane 3 ). In contrast, the amount of $B A M^{\triangle P 1 / P r o t A}$ 896 variant was considerably lower (lane 2). The asterisk indicates that BamE is 897 obtained from TEV digestion of BamE ${ }^{\text {ProtA }}$. 
898 (C) Cells overproducing the indicated variants of the BAM complex were

899 fractionated. The membrane and soluble fractions, obtained upon treatment of 900 collected cells with lysozyme and EDTA were analyzed by SDS-PAGE and 901 immunoblotting. BamA ${ }^{\Delta \mathrm{P} 1}$ was depleted from the total membrane fraction (lanes 1902 3), and accumulated in the soluble fraction containing the periplasmic protein DsbA 903 (lanes 4-6).

904

Fig. S5. Effect of lack or overproduction of DoIP on BAM localization.

906

BW25113 derivative cells harbouring a bamD-mCherry chromosomal fusion were

907 visualized on $1 \%(\mathrm{w} / \mathrm{v})$ agarose pads by fluorescence and phase-contrast

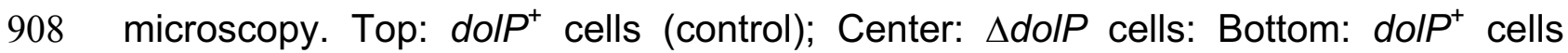
909 carrying $\mathrm{pDolP}{ }^{\mathrm{His}}$. Cells were cultured at $30^{\circ} \mathrm{C}$ in minimal $\mathrm{M} 9$ medium to $\mathrm{OD}_{600}=$ 910 0.5. IPTG $(400 \mu \mathrm{M})$ was supplemented for 1 hour to induce ectopic expression of 911 DolP ${ }^{\text {His }}$. Cells were visualized on $1 \%(\mathrm{w} / \mathrm{v})$ agarose pads by fluorescence and 912 phase-contrast microscopy. Bar $=5 \mu \mathrm{m}$.

914 Fig. S6. DolP accumulates at mid-cell sites during a late step of cell division.

915 (A) The total protein content of cells harbouring the dolP-gfp chromosomal fusion 916 (lanes 1) or wild-type doIP (lanes 2) were analyzed by SDS-PAGE followed by

917 coomassie staining or immunoblotting using a DolP specific antiserum.

918 (B, C) BW25113-derivative cells harbouring the chromosomal fusion dolP-gfp and 919 either zipA-mCherry $(\mathrm{B})$ or $n l p D-m$ Cherry $(\mathrm{C})$ were cultured at $30^{\circ} \mathrm{C}$ in minimal $\mathrm{M} 9$ 920 medium to $\mathrm{OD}_{600}=0.2-0.3$ and visualized on $1 \%(\mathrm{w} / \mathrm{v})$ agarose pads by

921 fluorescence and phase-contrast microscopy. Bar $=5 \mu \mathrm{m}$. 

and ZipA.

(A) BW25113-derivative cells harbouring the chromosomal fusion dolP-gfp and zipA-mCherry or nlpD-mCherry were transformed with pBAM $^{\text {His }}$ (ectopic overproduction of all BAM subunits, with His-tagged BamE). Cells were then cultured at $30^{\circ} \mathrm{C}$ in minimal M9 medium supplemented with $400 \mu \mathrm{M}$ IPTG for 1 hour until $\mathrm{OD}_{600}=0.2-0.3$, and visualized on $1 \%(\mathrm{w} / \mathrm{v})$ agarose pads by fluorescence

930 microscopy. The arrowheads indicate the localization of DolP ${ }^{\text {GFP }}$, ZipA ${ }^{\text {mCherry }}$ or $931 \quad$ NIpD ${ }^{\text {mCherry }}$ at division septa.

932 (B) Top: BW25113-derivative dolP-gfp cells transformed with pOmpA (ectopic 933 overproduction of His-tagged OmpA) were culture in LB medium and supplemented with $400 \mu \mathrm{M}$ IPTG or no IPTG for 1 hour prior to collecting cells. The total protein content was analyzed by SDS-PAGE and immunoblotting using the indicated antisera. Bottom: BW25113-derivative dolP-gfp cells transformed with pOmpA ${ }^{\text {His }}$ were cultured in minimal M9 medium supplemented with $400 \mu \mathrm{M}$ IPTG for 1 hour

938 until $\mathrm{OD}_{600}=0.2-0.3$, and visualized $(\mathrm{A})$. Bar $=5 \mu \mathrm{m}$.

939 (C) BW25113-derivative cells harbouring the chromosomal fusion dolP-gfp and 940 zipA-mCherry or nlpD-mCherry were transformed with $\mathrm{pBamA}^{\text {His }}$ (ectopic 941 overproduction of a partially inactive His-tagged form of BamA). Cells were then cultured at $30^{\circ} \mathrm{C}$ in minimal M9 medium supplemented with $400 \mu \mathrm{M}$ IPTG for 1 hour until $\mathrm{OD}_{600}=0.2-0.3$, and visualized as in $(A)$.

Fig. S8. BamA overaccumulation in the OM impairs septal DoIP localization.

946 (A) The JCM166 BamA depletion strain or its transformants carrying plasmids 947 encoding BamA ${ }^{\text {His }}$ or wild-type BamA and DolP ${ }^{\text {His }}$ were cultured in the presence of $9480.02 \%(\mathrm{w} / \mathrm{v})$ arabinose (which induces transcription of a chromosomal copy of wild949 type bamA engineered downstream of an arabinose-inducible $\mathrm{P}_{\text {bad }}$ promoter). Serial 
dilutions were spotted on LB agar devoid of or supplemented with $0.02 \%(\mathrm{w} / \mathrm{v})$ arabinose, as indicated. In the absence of arabinose, growth is supported by the ectopic expression of wild-type BamA and not of its variant encoding C-terminally His-tagged BamA.

954 (B) Overnight cultures of BW25113 cells harboring the chromosomal dolP-gfp fusion and carrying the indicated plasmids were diluted in minimal M9 medium supplemented with $400 \mu \mathrm{M}$ IPTG. The cells were grown at $30^{\circ} \mathrm{C}$ to $\mathrm{OD}_{600}=0.2-0.3$ and visualized on $1 \%(\mathrm{w} / \mathrm{v})$ agarose pads by fluorescence microscopy. The arrows indicate envelope constriction sites between forming daughter cells. Bar $=5 \mu \mathrm{m}$.

(C) Counting of BW25113 cells presenting septal DolP ${ }^{\text {GFP }}$ fluorescent signals. dolPgfp cells carring $\mathrm{pBAM}^{\mathrm{His}}, \mathrm{pBam}^{\mathrm{His}}, \mathrm{pBamA}^{\Delta \mathrm{P} 1 / \mathrm{His}}$ or $\mathrm{pBam}^{\Delta \mathrm{P} 2 / \mathrm{His}}$ (analyzed by fluorescence microscopy and shown in Fig. 5A and in Fig. S8B) were counted. The

962 percentage of cells presenting fluorescent DolPGFP signals at the mid-cell in samples overproducing all five BAM subunits or only one of the indicated BamA variants was normalized to the same fraction obtained for cells carrying the control empty vector (pCtrl). Bar charts display a mean value \pm SD $(n=3)$. More than 300 cells were counted in each experiment.

967 (D) BW25113 cells carrying the indicated plasmids were cultured and supplemented 968 with $400 \mu \mathrm{M}$ IPTG to induce ectopic expression of BamA ${ }^{\text {His }}$ and its mutant forms. 969 Collected cells were subjected to lysozyme/EDTA lysis to obtain the total membrane

970 and soluble fractions. The protein contents of the indicated cell fractions were separated by SDS-PAGE and immunolabeled with the indicated antisera.

972

973 Fig. S9. Envelope stress influences DolP localization

974 (A) Overnight cultures of BW25113 (Control) or $\Delta$ surA derivative cells carrying the 975 dolP-gfp chromosomal fusion were freshly diluted in M9 medium and incubated at $97630^{\circ} \mathrm{C}$ till $\mathrm{OD}_{600}=0.03$ and visualized on $1 \%(\mathrm{w} / \mathrm{v})$ agarose pads by contrast and 
977 fluorescence microscopy. Bar $=5 \mu \mathrm{m}$. The arrows indicate envelope constriction

978 sites between forming daughter cells. The percentage of cells presenting 979 fluorescent DolP ${ }^{\text {GFP }}$ signals at division septa in $\triangle$ surA cells was normalized to the 980 same fraction obtained for the control cells and reported below the micrograph.

981 More than 1000 cells were counted in each sample.

982 (B) Overnight cultures of BW25113 (control) or $\Delta$ surA derivative cells carrying the 983 dolP-gfp and $n / p D$-mCherry chromosomal fusions were freshly diluted in LB medium 984 and incubated at $30^{\circ} \mathrm{C}$ until $\mathrm{OD}_{600}=0.3$ prior to visualization by contrast and 985 fluorescence microscopy. Bar $=5 \mu \mathrm{m}$. The arrows indicate envelope constriction 986 sites between forming daughter cells

987 (C) Overnight cultures of $\triangle$ bamB cells harboring the chromosomal dolP-gfp fusion 988 were diluted in minimal $\mathrm{M} 9$ medium, cultured at $30^{\circ} \mathrm{C}$ to $\mathrm{OD}_{600}=0.3$ and visualized 989 on $1 \%(\mathrm{w} / \mathrm{v})$ agarose pads by contrast and fluorescence microscopy. The arrows 990 indicate envelope constriction sites between forming daughter cells. Bar $=5 \mu \mathrm{m}$.

991 The percentage of cells presenting fluorescent DoIP ${ }^{\text {GFP }}$ signals at division septa in $992 \Delta$ bamB cells was normalized to the same fraction obtained for the control cells 993 (BW25113 carrying the dolP-gfp chromosomal fusion) and reported below the 994 micrograph. More than 300 cells were counted. 
996 Table S1. Log2FC values of sgRNAs in the WT or $\Delta$ doIP screen.

997 See source data file (Table S1)

998

999 Table S2. Genetic interaction scores.

1000 See source data file (Table S2)

1001 


\begin{tabular}{|c|c|c|}
\hline Name & Genotype and relevant features & Source \\
\hline BW25113 & $\begin{array}{l}\Delta(\text { araD-araB }) 567 \Delta(r h a D-r h a B) 568 \\
\Delta \text { lacZ4787(::rrnB-3) hsdR514 rph-1 (wild-type } \\
\text { reference) }\end{array}$ & $\begin{array}{l}\text { Grenier et } \\
\text { al., } 2014^{74}\end{array}$ \\
\hline$\Delta r s e A$ & BW25113 rseA::kan & This study \\
\hline$\Delta d o l P$ & BW25113 dolP::kan & This study \\
\hline$\Delta b a m B$ & BW25113 bamB::kan & This study \\
\hline$\Delta$ bamB $\Delta d o l P$ & BW25113 $\Delta$ bamB dolP::kan & This study \\
\hline$\Delta d o l P \Delta r s e A$ & BW25113 $\Delta d o l P$ rseA::kan & This study \\
\hline$\Delta s k p$ & BW25113 skp::kan & This study \\
\hline$\Delta d o l P \Delta s k p$ & BW25113 $\Delta d o l P$ skp::kan & This study \\
\hline$\Delta d e g P$ & BW25113 degP::kan & This study \\
\hline$\Delta d o l P \Delta d e g P$ & BW25113 $\Delta$ dolP degP::kan & This study \\
\hline dolP-gfp & BW25113 dolP-gfp & This study \\
\hline$\Delta$ surA & BW25113 surA::kan & This study \\
\hline$\Delta s u r A$ dolP-gfp & BW25113 surA::kan dolP-gfp & This study \\
\hline$\Delta b a m B$ dolP-gfp & BW25113 bamB::kan dolP-gfp & This study \\
\hline $\begin{array}{l}\triangle d o l P \\
\text { bamD-mCherry }\end{array}$ & BW25113 $\Delta d o l P$ bamD-mCherry & This study \\
\hline bamD-mCherry & BW25113 bamD-mCherry & This study \\
\hline $\begin{array}{l}\text { dolP-gfp } \\
\text { nlpD-mCherry }\end{array}$ & BW25113 dolP-gfp nlpD-mCherry & This study \\
\hline $\begin{array}{l}\text { AsurA dolP-gfp } \\
\text { nlpD-mCherry }\end{array}$ & BW25113 dolP-gfp nlpD-mCherry surA::kan & This study \\
\hline $\begin{array}{l}\text { dolP-gfp } \\
\text { zipA-mCherry }\end{array}$ & BW25113 dolP-gfp zipA-mCherry & This study \\
\hline JCM166 & 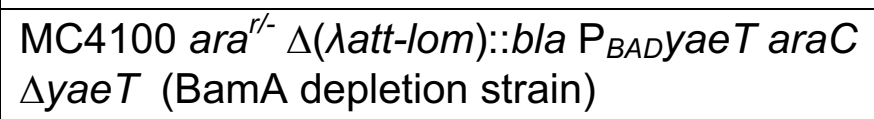 & $\begin{array}{l}\text { Wu et al., } \\
2005^{19}\end{array}$ \\
\hline LC-E75 & $\begin{array}{l}\mathrm{F}^{-} \lambda^{-} i l v G^{-} \text {rfb-50 rph-1 186attB:: } \mathrm{P}_{\text {tet }} \text {-dcas9, } \\
\lambda \text { attB::mCherry }\end{array}$ & $\begin{array}{l}\text { Cui et al., } \\
2018^{38}\end{array}$ \\
\hline LC-E75 $\Delta d o l P$ & LC-E75 dolP::kan & This study \\
\hline
\end{tabular}


Table S4: List of plasmids

\begin{tabular}{|c|c|c|}
\hline Name & Relevant features & Source \\
\hline pCtrl & $\begin{array}{l}\text { Reference empty vector for ectopic } \\
\text { protein expression }\end{array}$ & This study \\
\hline pBAM & Ectopic expression of all 5 BAM subunits & This study \\
\hline $\begin{array}{l}\mathrm{pBAM}^{\mathrm{His}} \\
(\mathrm{pJH} 114)\end{array}$ & $\begin{array}{l}\text { Ectopic expression of all } 5 \text { BAM subunits; } \\
\text { BamE is C-terminally His-tagged }\end{array}$ & $\begin{array}{l}\text { Roman } \\
\text { Hernandez et } \\
\text { al., } 2014^{55}\end{array}$ \\
\hline pBAM $^{\text {ProtA }}$ & $\begin{array}{l}\text { Ectopic expression of all } 5 \text { BAM subunits; } \\
\text { BamE is C-terminally Protein A-tagged; a } \\
\text { TEV site amino acid linker is positioned } \\
\text { immediately upstream of the tag }\end{array}$ & This study \\
\hline $\mathrm{pBAM}^{\triangle \mathrm{P} 1 / \text { ProtA }}$ & $\begin{array}{l}\text { Ectopic expression of all } 5 \text { BAM subunits; } \\
\text { BamA harbours the deletion of POTRA1 } \\
\text { and BamE is C-terminally Protein A- } \\
\text { tagged; a TEV site amino acid linker is } \\
\text { positioned immediately upstream of the } \\
\text { tag }\end{array}$ & This study \\
\hline pBAM $^{\mathrm{AP} 2 / \text { ProtA }}$ & $\begin{array}{l}\text { Ectopic expression of all } 5 \text { BAM subunits; } \\
\text { BamA harbours the deletion of POTRA2 } \\
\text { and BamE is C-terminally Protein A- } \\
\text { tagged; a TEV site amino acid linker is } \\
\text { positioned immediately upstream of the } \\
\text { tag }\end{array}$ & This study \\
\hline pBamABDE $^{\text {His }}$ & $\begin{array}{l}\text { Ectopic expression of BamA, BamB, } \\
\text { BamD and BamE subunits; BamE is C- } \\
\text { terminally His-tagged }\end{array}$ & This study \\
\hline pBamACDE $^{\text {His }}$ & $\begin{array}{l}\text { Ectopic expression of BamA, BamC, } \\
\text { BamD and BamE subunits; BamE is C- } \\
\text { terminally His-tagged }\end{array}$ & This study \\
\hline
\end{tabular}




\begin{tabular}{|c|c|c|}
\hline pBamBCDE $^{\text {His }}$ & $\begin{array}{l}\text { Ectopic expression of BamB, BamC, } \\
\text { BamD and BamE subunits; BamE is C- } \\
\text { terminally His-tagged }\end{array}$ & This study \\
\hline pBamCDE $^{\text {His }}$ & $\begin{array}{l}\text { Ectopic expression of BamC, BamD and } \\
\text { BamE subunits; BamE is C-terminally } \\
\text { His-tagged }\end{array}$ & This study \\
\hline pBamA & Ectopic expression of wild-type BamA & This study \\
\hline pBamA $^{\text {His }}$ & $\begin{array}{l}\text { Ectopic expression of C-terminally His- } \\
\text { tagged BamA }\end{array}$ & This study \\
\hline $\mathrm{pBamA}^{\Delta \mathrm{P} 1 / \mathrm{His}}$ & $\begin{array}{l}\text { Ectopic expression of a C-terminally His- } \\
\text { tagged BamA variant lacking POTRA1 }\end{array}$ & This study \\
\hline $\mathrm{pBamA}^{\Delta \mathrm{P} 2 / \mathrm{His}}$ & $\begin{array}{l}\text { Ectopic expression of a C-terminally His- } \\
\text { tagged BamA variant lacking POTRA2 }\end{array}$ & This study \\
\hline pBamA-DolP ${ }^{\mathrm{His}}$ & $\begin{array}{l}\text { Ectopic expression of BamA and C- } \\
\text { terminally His-tagged DolP }\end{array}$ & This study \\
\hline $\mathrm{pBamA}^{\Delta \mathrm{P} 1}$-DolP $\mathrm{P}^{\mathrm{His}}$ & $\begin{array}{l}\text { Ectopic expression of a BamA variant } \\
\text { lacking POTRA1 and C-terminally His- } \\
\text { tagged DoIP }\end{array}$ & This study \\
\hline $\mathrm{pBamA}^{\Delta \mathrm{P} 2}$-DolP $\mathrm{P}^{\mathrm{His}}$ & $\begin{array}{l}\text { Ectopic expression of a BamA variant } \\
\text { lacking POTRA2 and C-terminally His- } \\
\text { tagged DolP }\end{array}$ & This study \\
\hline pDolP & Ectopic expression of wild-type DolP & This study \\
\hline pDolP ProtA & $\begin{array}{l}\text { Ectopic expression of C-terminally protein } \\
\text { A-tagged DoIP; a TEV site amino acid } \\
\text { linker is positioned immediately upstream } \\
\text { of the tag }\end{array}$ & This study \\
\hline $\mathrm{pDolP}^{\mathrm{His}}$ & $\begin{array}{l}\text { Ectopic expression of C-terminally His- } \\
\text { tagged DolP }\end{array}$ & This study \\
\hline $\mathrm{pOmpA}^{\mathrm{His}}$ & $\begin{array}{l}\text { Ectopic expression of C-terminally His- } \\
\text { tagged OmpA }\end{array}$ & This study \\
\hline
\end{tabular}




\begin{tabular}{|l|l|l|}
\hline pRI22 & Ectopic expression of EspP & $\begin{array}{l}\text { leva et al., } \\
2009^{79}\end{array}$ \\
\hline psgRNAcos & $\begin{array}{l}\text { Reference empty vector for expression of } \\
\text { sgRNAs }\end{array}$ & $\begin{array}{l}\text { Cui et al., } 2018 \\
38\end{array}$ \\
\hline $\begin{array}{l}\text { psgRNAbamD } \\
\text { pCAT187) }\end{array}$ & Expression of a bamD-specific sgRNA & This study \\
\hline $\begin{array}{l}\text { psgRNAbamE } \\
\text { pCAT189) }\end{array}$ & Expression of a bamE-specific sgRNA & This study \\
\hline $\begin{array}{l}\text { psgRNAenvC } \\
\text { pCAT191) }\end{array}$ & Expression of a envC-specific sgRNA & This study \\
\hline $\begin{array}{l}\text { psgRNAfts } X \\
\text { (pCAT193) }\end{array}$ & Expression of a ftsX-specific sgRNA & This study \\
\hline
\end{tabular}

1007

1008 


\section{References}

10101 den Blaauwen, T., Hamoen, L. W. \& Levin, P. A. The divisome at 25: the road ahead. Current opinion in microbiology 36, 85-94, doi:10.1016/j.mib.2017.01.007 (2017). synthesis and remodelling. doi:10.1038/s41579-020-0366-3 (2020). Calmettes, C., Judd, A. \& Moraes, T. F. Structural Aspects of Bacterial Outer Membrane Protein Assembly. Advances in experimental medicine and biology 883, 255-270, doi:10.1007/978-3-319-23603-2_14 (2015).

5 Ranava, D., Caumont-Sarcos, A., Albenne, C. \& leva, R. Bacterial Nikaido, $H$. Molecular basis of bacterial outer membrane permeability revisited. Microbiology and molecular biology reviews : MMBR 67, 593-656, doi:10.1128/mmbr.67.4.593-656.2003 (2003). 6 FEMS microbiology letters 365, doi:10.1093/femsle/fny087 (2018). machineries for the assembly of membrane-embedded beta-barrel proteins.

folding from an energy landscape perspective. BMC biology 15, 123, doi:10.1186/s12915-017-0464-5 (2017).

7 Webb, C. T., Heinz, E. \& Lithgow, T. Evolution of the beta-barrel assembly machinery. Trends in microbiology 20, 612-620, doi:10.1016/j.tim.2012.08.006 (2012).

8 Voulhoux, R., Bos, M. P., Geurtsen, J., Mols, M. \& Tommassen, J. Role of a highly conserved bacterial protein in outer membrane protein assembly. Science (New York, N.Y.) 299, 262-265, doi:10.1126/science.1078973 (2003).

9 Noinaj, N., Kuszak, A. J., Gumbart, J. C., Lukacik, P., Chang, H., Easley, N. C., Lithgow, T. \& Buchanan, S. K. Structural insight into the biogenesis of beta-barrel membrane proteins. Nature 501, 385-390, doi:10.1038/nature12521 (2013).

10 ladanza, M. G., Higgins, A. J., Schiffrin, B., Calabrese, A. N., Brockwell, D. J., Ashcroft, A. E., Radford, S. E. \& Ranson, N. A. Lateral opening in the intact beta-barrel assembly machinery captured by cryo-EM. Nature communications 7, 12865, doi:10.1038/ncomms12865 (2016).

11 Gu, Y., Li, H., Dong, H., Zeng, Y., Zhang, Z., Paterson, N. G., Stansfeld, P. J., Wang, Z., Zhang, Y., Wang, W. \& Dong, C. Structural basis of outer membrane protein insertion by the BAM complex. Nature 531, 64-69, doi:10.1038/nature17199 (2016).

12 Bakelar, J., Buchanan, S. K. \& Noinaj, N. The structure of the beta-barrel assembly machinery complex. Science (New York, N.Y.) 351, 180-186, doi:10.1126/science.aad3460 (2016).

13 Doerner, P. A. \& Sousa, M. C. Extreme Dynamics in the BamA beta-Barrel Seam. Biochemistry 56, 3142-3149, doi:10.1021/acs.biochem.7b00281 (2017).

14 Gessmann, D., Chung, Y. H., Danoff, E. J., Plummer, A. M., Sandlin, C. W., Zaccai, N. R. \& Fleming, K. G. Outer membrane beta-barrel protein folding is physically controlled by periplasmic lipid head groups and BamA. Proceedings of the National Academy of Sciences of the United States of America 111, 5878-5883, doi:10.1073/pnas.1322473111 (2014). 
15 Doyle, M. T. \& Bernstein, H. D. Bacterial outer membrane proteins assemble via asymmetric interactions with the BamA beta-barrel. Nature communications 10, 3358, doi:10.1038/s41467-019-11230-9 (2019).

16 Tomasek, D., Rawson, S., Lee, J., Wzorek, J. S., Harrison, S. C., Li, Z. \& Kahne, D. Structure of a nascent membrane protein as it folds on the BAM complex. Nature, doi:10.1038/s41586-020-2370-1 (2020).

17 Sklar, J. G., Wu, T., Gronenberg, L. S., Malinverni, J. C., Kahne, D. \& Silhavy, T. J. Lipoprotein SmpA is a component of the YaeT complex that assembles outer membrane proteins in Escherichia coli. Proceedings of the National Academy of Sciences of the United States of America 104, 64006405, doi:10.1073/pnas.0701579104 (2007).

18 Kim, S., Malinverni, J. C., Sliz, P., Silhavy, T. J., Harrison, S. C. \& Kahne, D. Structure and function of an essential component of the outer membrane protein assembly machine. Science (New York, N.Y.) 317, 961-964, doi:10.1126/science.1143993 (2007).

19 Wu, T., Malinverni, J., Ruiz, N., Kim, S., Silhavy, T. J. \& Kahne, D. Identification of a multicomponent complex required for outer membrane biogenesis in Escherichia coli. Cell 121, 235-245, doi:10.1016/j.cell.2005.02.015 (2005).

20 Bennion, D., Charlson, E. S., Coon, E. \& Misra, R. Dissection of beta-barrel outer membrane protein assembly pathways through characterizing BamA POTRA 1 mutants of Escherichia coli. Molecular microbiology 77, 11531171, doi:10.1111/j.1365-2958.2010.07280.x (2010).

21 Rizzitello, A. E., Harper, J. R. \& Silhavy, T. J. Genetic evidence for parallel pathways of chaperone activity in the periplasm of Escherichia coli. Journal of bacteriology 183, 6794-6800, doi:10.1128/jb.183.23.6794-6800.2001 (2001).

22 Crane, J. M. \& Randall, L. L. The Sec System: Protein Export in Escherichia coli. EcoSal Plus 7, doi:10.1128/ecosalplus.ESP-0002-2017 (2017).

23 Walsh, N. P., Alba, B. M., Bose, B., Gross, C. A. \& Sauer, R. T. OMP peptide signals initiate the envelope-stress response by activating DegS protease via relief of inhibition mediated by its PDZ domain. Cell 113, 61-71, doi:10.1016/s0092-8674(03)00203-4 (2003).

24 Ades, S. E. Regulation by destruction: design of the sigmaE envelope stress response. Current opinion in microbiology 11, 535-540, doi:10.1016/j.mib.2008.10.004 (2008).

25 Rhodius, V. A., Suh, W. C., Nonaka, G., West, J. \& Gross, C. A. Conserved and variable functions of the sigmaE stress response in related genomes. PLoS biology 4, e2, doi:10.1371/journal.pbio.0040002 (2006).

26 Guillier, M., Gottesman, S. \& Storz, G. Modulating the outer membrane with small RNAs. Genes \& development 20, 2338-2348, doi:10.1101/gad.1457506 (2006).

27 De Las Penas, A., Connolly, L. \& Gross, C. A. SigmaE is an essential sigma factor in Escherichia coli. Journal of bacteriology 179, 6862-6864, doi:10.1128/jb.179.21.6862-6864.1997 (1997).

28 Missiakas, D., Mayer, M. P., Lemaire, M., Georgopoulos, C. \& Raina, S. Modulation of the Escherichia coli sigmaE (RpoE) heat-shock transcriptionfactor activity by the RseA, RseB and RseC proteins. Molecular microbiology 24, 355-371, doi:10.1046/j.1365-2958.1997.3601713.x (1997). 
110729 De Las Penas, A., Connolly, L. \& Gross, C. A. The sigmaE-mediated

1108

1109

1110

1111

1112

1113

1114

1115

1116

1117

1118

1119

1120

1121

1122

1123

1124

1125

1126

1127

1128

1129

1130

1131

1132

1133

1134

1135

1136

1137

1138

1139

1140

1141

1142

1143

1144

1145

1146

1147

1148

1149

1150

1151

1152

1153

1154

1155

1156

response to extracytoplasmic stress in Escherichia coli is transduced by RseA and RseB, two negative regulators of sigmaE. Molecular microbiology 24, 373-385, doi:10.1046/j.1365-2958.1997.3611718.x (1997).

30 Nicoloff, H., Gopalkrishnan, S. \& Ades, S. E. Appropriate Regulation of the sigma(E)-Dependent Envelope Stress Response Is Necessary To Maintain Cell Envelope Integrity and Stationary-Phase Survival in Escherichia coli. Journal of bacteriology 199, doi:10.1128/jb.00089-17 (2017).

31 Mitchell, A. M. \& Silhavy, T. J. Envelope stress responses: balancing damage repair and toxicity. Nature reviews. Microbiology 17, 417-428, doi:10.1038/s41579-019-0199-0 (2019).

32 Morris, F. C., Wells, T. J., Bryant, J. A., Schager, A. E., Sevastsyanovich, Y. R., Squire, D. J. P., Marshall, J., Isom, G. L., Rooke, J., Maderbocus, R., Knowles, T. J., Overduin, M., Rossiter, A. E., Cunningham, A. F. \& Henderson, I. R. YraP Contributes to Cell Envelope Integrity and Virulence of Salmonella enterica Serovar Typhimurium. Infection and immunity 86, doi:10.1128/iai.00829-17 (2018).

33 Tsang, M. J., Yakhnina, A. A. \& Bernhardt, T. G. NIpD links cell wall remodeling and outer membrane invagination during cytokinesis in Escherichia coli. PLoS genetics 13, e1006888, doi:10.1371/journal.pgen.1006888 (2017).

34 Onufryk, C., Crouch, M. L., Fang, F. C. \& Gross, C. A. Characterization of six lipoproteins in the sigmaE regulon. Journal of bacteriology 187, 4552-4561, doi:10.1128/jb.187.13.4552-4561.2005 (2005).

35 Seib, K. L., Haag, A. F., Oriente, F., Fantappie, L., Borghi, S., Semchenko, E. A., Schulz, B. L., Ferlicca, F., Taddei, A. R., Giuliani, M. M., Pizza, M. \& Delany, I. The meningococcal vaccine antigen GNA2091 is an analogue of YraP and plays key roles in outer membrane stability and virulence. FASEB journal : official publication of the Federation of American Societies for Experimental Biology 33, 12324-12335, doi:10.1096/fj.201900669R (2019).

36 Bos, M. P., Grijpstra, J., Tommassen-van Boxtel, R. \& Tommassen, J. Involvement of Neisseria meningitidis lipoprotein GNA2091 in the assembly of a subset of outer membrane proteins. The Journal of biological chemistry 289, 15602-15610, doi:10.1074/jbc.M113.539510 (2014).

37 Baba, T., Ara, T., Hasegawa, M., Takai, Y., Okumura, Y., Baba, M., Datsenko, K. A., Tomita, M., Wanner, B. L. \& Mori, H. Construction of Escherichia coli K-12 in-frame, single-gene knockout mutants: the Keio collection. Molecular systems biology 2, 2006.0008, doi:10.1038/msb4100050 (2006).

38 Cui, L., Vigouroux, A., Rousset, F., Varet, H., Khanna, V. \& Bikard, D. A CRISPRi screen in E. coli reveals sequence-specific toxicity of dCas9. Nature communications 9, 1912, doi:10.1038/s41467-018-04209-5 (2018).

39 Calvo-Villamanan, A., Ng, J. W., Planel, R., Menager, H., Chen, A., Cui, L. \& Bikard, D. On-target activity predictions enable improved CRISPR-dCas9 screens in bacteria. Nucleic acids research, doi:10.1093/nar/gkaa294 (2020).

40 Pichoff, S., Du, S. \& Lutkenhaus, J. Roles of FtsEX in cell division. Research in microbiology 170, 374-380, doi:10.1016/j.resmic.2019.07.003 (2019).

41 Heidrich, C., Templin, M. F., Ursinus, A., Merdanovic, M., Berger, J., Schwarz, H., de Pedro, M. A. \& Holtje, J. V. Involvement of N-acetylmuramylL-alanine amidases in cell separation and antibiotic-induced autolysis of 
Escherichia coli. Molecular microbiology 41, 167-178, doi:10.1046/j.13652958.2001.02499.x (2001).

42 Uehara, T., Dinh, T. \& Bernhardt, T. G. LytM-domain factors are required for daughter cell separation and rapid ampicillin-induced lysis in Escherichia coli. Journal of bacteriology 191, 5094-5107, doi:10.1128/jb.00505-09 (2009).

43 Yang, D. C., Peters, N. T., Parzych, K. R., Uehara, T., Markovski, M. \& Bernhardt, T. G. An ATP-binding cassette transporter-like complex governs cell-wall hydrolysis at the bacterial cytokinetic ring. Proceedings of the National Academy of Sciences of the United States of America 108, E10521060, doi:10.1073/pnas.1107780108 (2011).

44 Uehara, T., Parzych, K. R., Dinh, T. \& Bernhardt, T. G. Daughter cell separation is controlled by cytokinetic ring-activated cell wall hydrolysis. The EMBO journal 29, 1412-1422, doi:10.1038/emboj.2010.36 (2010).

45 Chung, H. S., Yao, Z., Goehring, N. W., Kishony, R., Beckwith, J. \& Kahne, D. Rapid beta-lactam-induced lysis requires successful assembly of the cell division machinery. Proceedings of the National Academy of Sciences of the United States of America 106, 21872-21877, doi:10.1073/pnas.0911674106 (2009).

46 Malinverni, J. C., Werner, J., Kim, S., Sklar, J. G., Kahne, D., Misra, R. \& Silhavy, T. J. YfiO stabilizes the YaeT complex and is essential for outer membrane protein assembly in Escherichia coli. Molecular microbiology 61, 151-164, doi:10.1111/j.1365-2958.2006.05211.x (2006).

47 Carlson, M. L., Stacey, R. G., Young, J. W., Wason, I. S., Zhao, Z., Rattray, D. G., Scott, N., Kerr, C. H., Babu, M., Foster, L. J. \& Duong Van Hoa, F. Profiling the Escherichia coli membrane protein interactome captured in Peptidisc libraries. eLife 8, doi:10.7554/eLife.46615 (2019).

48 Alvira, S., Watkins, D. W., Troman, L., Allen, W. J., Lorriman, J., Degliesposti, G., Cohen, E. J., Beeby, M., Daum, B., Gold, V. A. M., Skehel, J. M. \& Collinson, I. Inter-membrane association of the Sec and BAM translocons for bacterial outer-membrane biogenesis. bioRxiv, 589077, doi:10.1101/589077 (2020).

49 Li, G. W., Burkhardt, D., Gross, C. \& Weissman, J. S. Quantifying absolute protein synthesis rates reveals principles underlying allocation of cellular resources. Cell 157, 624-635, doi:10.1016/j.cell.2014.02.033 (2014).

50 Nakamura, K. \& Mizushima, S. Effects of heating in dodecyl sulfate solution on the conformation and electrophoretic mobility of isolated major outer membrane proteins from Escherichia coli K-12. Journal of biochemistry 80, 1411-1422, doi:10.1093/oxfordjournals.jbchem.a131414 (1976).

51 Rouviere, P. E. \& Gross, C. A. SurA, a periplasmic protein with peptidyl-prolyl isomerase activity, participates in the assembly of outer membrane porins. Genes \& development 10, 3170-3182, doi:10.1101/gad.10.24.3170 (1996).

52 Charlson, E. S., Werner, J. N. \& Misra, R. Differential effects of yfgL mutation on Escherichia coli outer membrane proteins and lipopolysaccharide. Journal of bacteriology 188, 7186-7194, doi:10.1128/jb.00571-06 (2006).

53 Guo, M. S., Updegrove, T. B., Gogol, E. B., Shabalina, S. A., Gross, C. A. \& Storz, G. MicL, a new $\sigma E-d e p e n d e n t ~ s R N A$, combats envelope stress by repressing synthesis of Lpp, the major outer membrane lipoprotein. Genes \& development 28, 1620-1634, doi:10.1101/gad.243485.114 (2014).

54 Gogol, E. B., Rhodius, V. A., Papenfort, K., Vogel, J. \& Gross, C. A. Small RNAs endow a transcriptional activator with essential repressor functions for 
single-tier control of a global stress regulon. Proceedings of the National Academy of Sciences of the United States of America 108, 12875-12880, doi:10.1073/pnas.1109379108 (2011).

55 Roman-Hernandez, G., Peterson, J. H. \& Bernstein, H. D. Reconstitution of bacterial autotransporter assembly using purified components. eLife 3, e04234, doi:10.7554/eLife.04234 (2014).

56 Hale, C. A. \& de Boer, P. A. Direct binding of FtsZ to ZipA, an essential component of the septal ring structure that mediates cell division in $\mathrm{E}$. coli. Cell 88, 175-185, doi:10.1016/s0092-8674(00)81838-3 (1997).

57 Hartmann, J. B., Zahn, M., Burmann, I. M., Bibow, S. \& Hiller, S. SequenceSpecific Solution NMR Assignments of the beta-Barrel Insertase BamA to Monitor Its Conformational Ensemble at the Atomic Level. Journal of the American Chemical Society 140, 11252-11260, doi:10.1021/jacs.8b03220 (2018).

58 Vertommen, D., Ruiz, N., Leverrier, P., Silhavy, T. J. \& Collet, J. F. Characterization of the role of the Escherichia coli periplasmic chaperone SurA using differential proteomics. Proteomics 9, 2432-2443, doi:10.1002/pmic.200800794 (2009).

59 Konovalova, A., Schwalm, J. A. \& Silhavy, T. J. A Suppressor Mutation That Creates a Faster and More Robust sigmaE Envelope Stress Response. Journal of bacteriology 198, 2345-2351, doi:10.1128/jb.00340-16 (2016).

60 Kern, B., Leiser, O. P. \& Misra, R. Suppressor Mutations in degS Overcome the Acute Temperature-Sensitive Phenotype of DeltadegP and DeltadegP Deltatol-pal Mutants of Escherichia coli. Journal of bacteriology 201, doi:10.1128/jb.00742-18 (2019).

61 Hart, E. M., O'Connell, A., Tang, K., Wzorek, J. S., Grabowicz, M., Kahne, D. \& Silhavy, T. J. Fine-Tuning of sigma(E) Activation Suppresses Multiple Assembly-Defective Mutations in Escherichia coli. Journal of bacteriology 201, doi:10.1128/jb.00745-18 (2019).

62 Leiser, O. P., Charlson, E. S., Gerken, H. \& Misra, R. Reversal of the $\Delta$ degP phenotypes by a novel rpoE allele of Escherichia coli. PloS one 7, e33979, doi:10.1371/journal.pone.0033979 (2012).

63 Yeats, C. \& Bateman, A. The BON domain: a putative membrane-binding domain. Trends in biochemical sciences 28, 352-355, doi:10.1016/s09680004(03)00115-4 (2003).

64 Bryant, J. A., Morris, F. C., Knowles, T. J., Maderbocus, R., Heinz, E., Boelter, G., Alodaini, D., Colyer, A., Wotherspoon, P. J., Staunton, K. A., Jeeves, M., Browning, D. F., Sevastsyanovich, Y. R., Wells, T. J., Rossiter, A. E., Bavro, V. N., Sridhar, P., Ward, D. G., Chong, Z. S., Icke, C., Teo, A., Chng, S. S., Roper, D. I., Lithgow, T., Cunningham, A. F., Banzhaf, M., Overduin, M. \& Henderson, I. R. Structure-function analyses of dual-BON domain protein DolP identifies phospholipid binding as a new mechanism for protein localisation. bioRxiv, 2020.2008.2010.244616, doi:10.1101/2020.08.10.244616 (2020).

65 Fleming, K. G. A combined kinetic push and thermodynamic pull as driving forces for outer membrane protein sorting and folding in bacteria. Philosophical transactions of the Royal Society of London. Series B, Biological sciences 370, doi:10.1098/rstb.2015.0026 (2015).

66 Horne, J. E., Brockwell, D. J. \& Radford, S. E. Role of the lipid bilayer in outer membrane protein folding in Gram-negative bacteria. The Journal of 
biological chemistry 295, 10340-10367, doi:10.1074/jbc.REV120.011473 (2020).

67 Sinnige, T., Weingarth, M., Renault, M., Baker, L., Tommassen, J. \& Baldus,

M. Solid-state NMR studies of full-length BamA in lipid bilayers suggest limited overall POTRA mobility. Journal of molecular biology 426, 2009-2021, doi:10.1016/j.jmb.2014.02.007 (2014). Rassam, P., Copeland, N. A., Birkholz, O., Tóth, C., Chavent, M., Duncan, A. L., Cross, S. J., Housden, N. G., Kaminska, R., Seger, U., Quinn, D. M., Garrod, T. J., Sansom, M. S., Piehler, J., Baumann, C. G. \& Kleanthous, C. Supramolecular assemblies underpin turnover of outer membrane proteins in bacteria. Nature 523, 333-336, doi:10.1038/nature14461 (2015).

69 Gunasinghe, S. D., Shiota, T., Stubenrauch, C. J., Schulze, K. E., Webb, C. T., Fulcher, A. J., Dunstan, R. A., Hay, I. D., Naderer, T., Whelan, D. R., Bell, WD40 Protein BamB Mediates Coupling of BAM Complexes into Assembly Precincts in the Bacterial Outer Membrane. Cell reports 23, 2782-2794, doi:10.1016/j.celrep.2018.04.093 (2018).

70 Jarosławski, S., Duquesne, K., Sturgis, J. N. \& Scheuring, S. High-resolution architecture of the outer membrane of the Gram-negative bacteria Roseobacter denitrificans. Molecular microbiology 74, 1211-1222, doi:10.1111/j.1365-2958.2009.06926.x (2009).

71 Lessen, H. J., Fleming, P. J., Fleming, K. G. \& Sodt, A. J. Building Blocks of the Outer Membrane: Calculating a General Elastic Energy Model for $\beta$ Barrel Membrane Proteins. Journal of chemical theory and computation 14, 4487-4497, doi:10.1021/acs.jctc.8b00377 (2018).

72 Cascales, E., Bernadac, A., Gavioli, M., Lazzaroni, J. C. \& Lloubes, R. Pal lipoprotein of Escherichia coli plays a major role in outer membrane integrity. Journal of bacteriology 184, 754-759, doi:10.1128/jb.184.3.754-759.2002 (2002).

73 Asmar, A. T. \& Collet, J. F. Lpp, the Braun lipoprotein, turns 50-major achievements and remaining issues. FEMS microbiology letters $\mathbf{3 6 5}$, doi:10.1093/femsle/fny199 (2018).

74 Grenier, F., Matteau, D., Baby, V. \& Rodrigue, S. Complete Genome Sequence of Escherichia coli BW25113. Genome announcements 2, doi:10.1128/genomeA.01038-14 (2014).

75 Blattner, F. R., Plunkett, G., 3rd, Bloch, C. A., Perna, N. T., Burland, V., Riley, M., Collado-Vides, J., Glasner, J. D., Rode, C. K., Mayhew, G. F., Gregor, J., Davis, N. W., Kirkpatrick, H. A., Goeden, M. A., Rose, D. J., Mau, B. \& Shao, Y. The complete genome sequence of Escherichia coli K-12. Science (New York, N.Y.) 277, 1453-1462, doi:10.1126/science.277.5331.1453 (1997).

76 Datsenko, K. A. \& Wanner, B. L. One-step inactivation of chromosomal genes in Escherichia coli K-12 using PCR products. Proceedings of the National Academy of Sciences of the United States of America 97, 66406645, doi:10.1073/pnas.120163297 (2000).

77 Knop, M., Siegers, K., Pereira, G., Zachariae, W., Winsor, B., Nasmyth, K. \& Schiebel, E. Epitope tagging of yeast genes using a PCR-based strategy: more tags and improved practical routines. Yeast (Chichester, England) 15, 963-972, yea399>3.0.Co;2-w (1999). 
78 McLeay, R. C. \& Bailey, T. L. Motif Enrichment Analysis: a unified framework and an evaluation on ChIP data. BMC bioinformatics 11, 165, doi:10.1186/1471-2105-11-165 (2010). 79 leva, R. \& Bernstein, H. D. Interaction of an autotransporter passenger membrane. Proceedings of the National Academy of Sciences of the United States of America 106, 19120-19125, doi:10.1073/pnas.0907912106 (2009). Vischer, N. O., Verheul, J., Postma, M., van den Berg van Saparoea, B., Galli, E., Natale, P., Gerdes, K., Luirink, J., Vollmer, W., Vicente, M. \& den Blaauwen, T. Cell age dependent concentration of Escherichia coli divisome proteins analyzed with ImageJ and ObjectJ. Frontiers in microbiology 6, 586, doi:10.3389/fmicb.2015.00586 (2015).

81 Ashburner, M., Ball, C. A., Blake, J. A., Botstein, D., Butler, H., Cherry, J. M., Davis, A. P., Dolinski, K., Dwight, S. S., Eppig, J. T., Harris, M. A., Hill, D. P., Issel-Tarver, L., Kasarskis, A., Lewis, S., Matese, J. C., Richardson, J. E., Ringwald, M., Rubin, G. M. \& Sherlock, G. Gene ontology: tool for the unification of biology. The Gene Ontology Consortium. Nature genetics 25, 25-29, doi:10.1038/75556 (2000).

82 Albenne, C. \& leva, R. Job contenders: roles of the beta-barrel assembly machinery and the translocation and assembly module in autotransporter secretion. Molecular microbiology 106, 505-517, doi:10.1111/mmi.13832 (2017).

83 Szabady, R. L., Peterson, J. H., Skillman, K. M. \& Bernstein, H. D. An unusual signal peptide facilitates late steps in the biogenesis of a bacterial autotransporter. Proceedings of the National Academy of Sciences of the United States of America 102, 221-226, doi:10.1073/pnas.0406055102 (2005). 
A

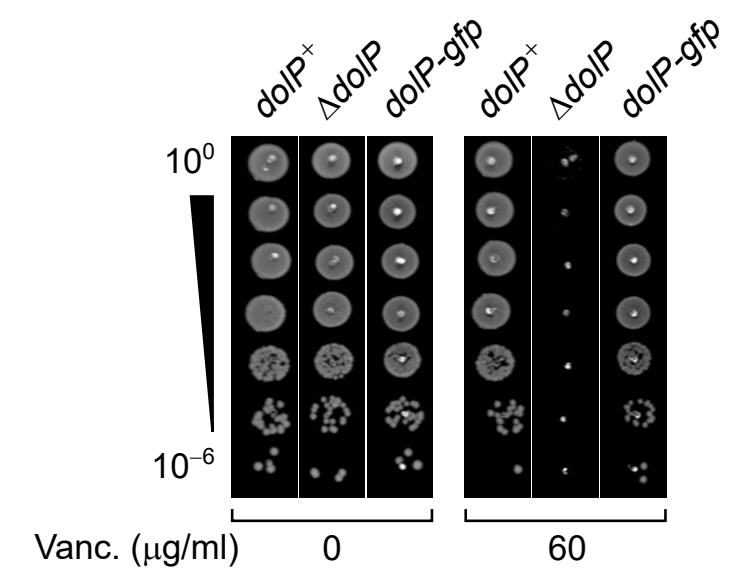

C

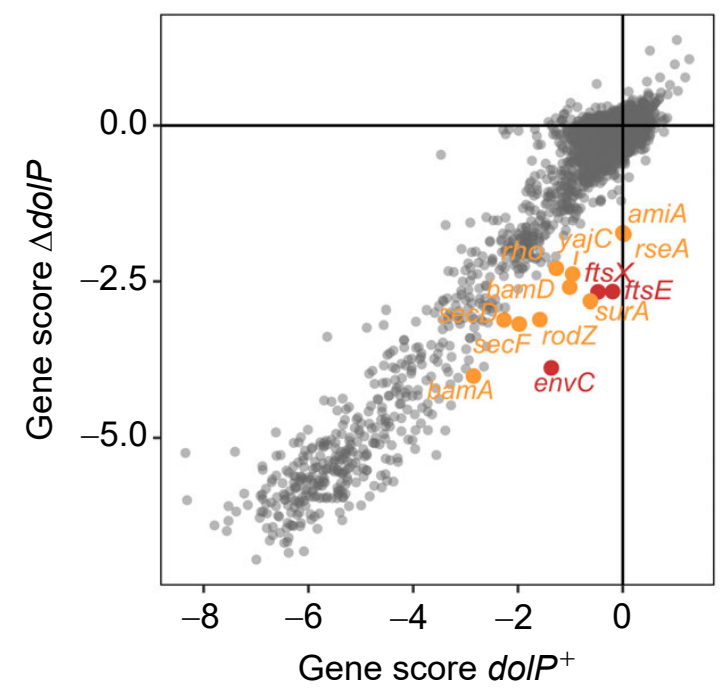

D

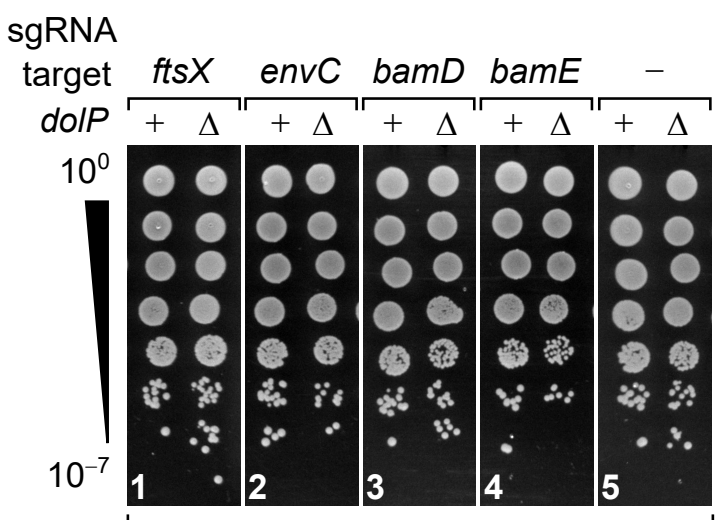

- aTc (no dCas9 induction)
B

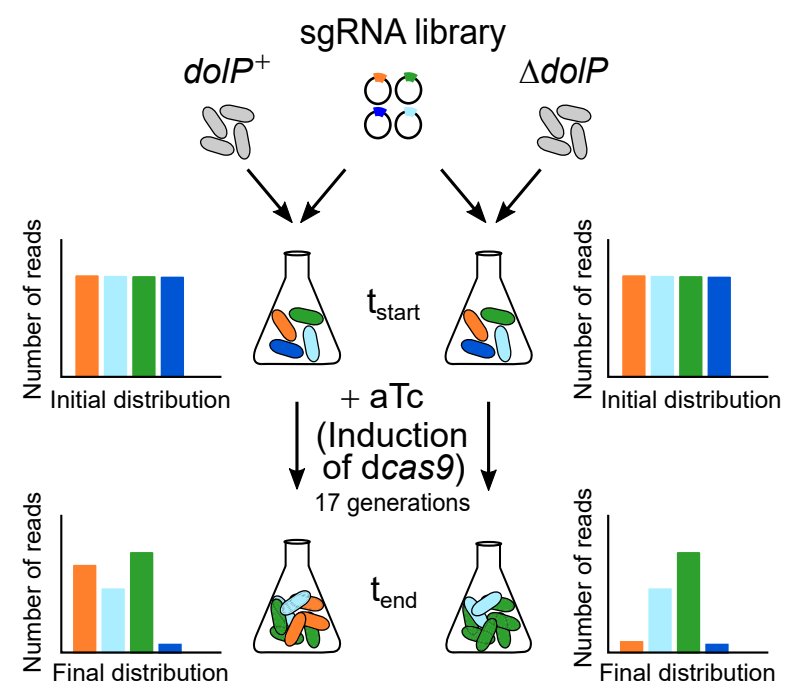

$\mathbf{E}$

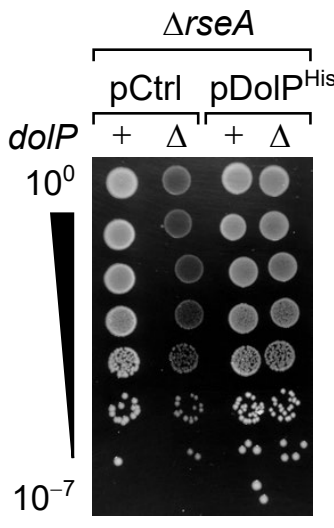

Figure 1. 
A

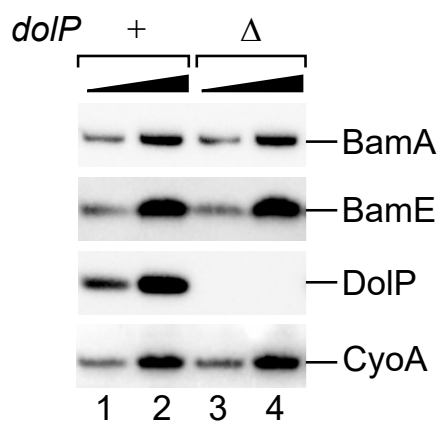

B

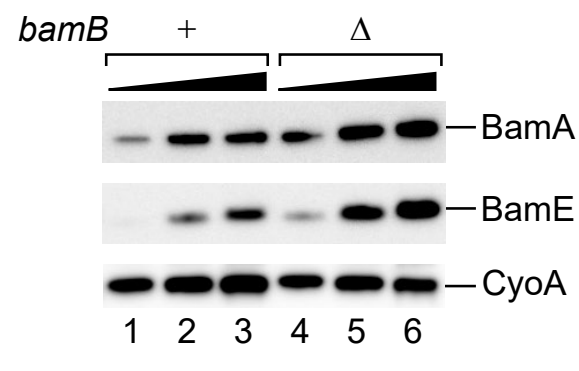

C

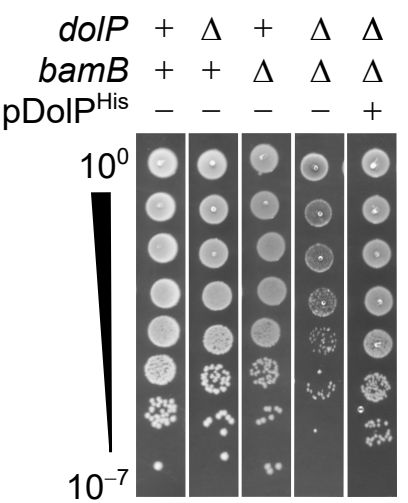

D
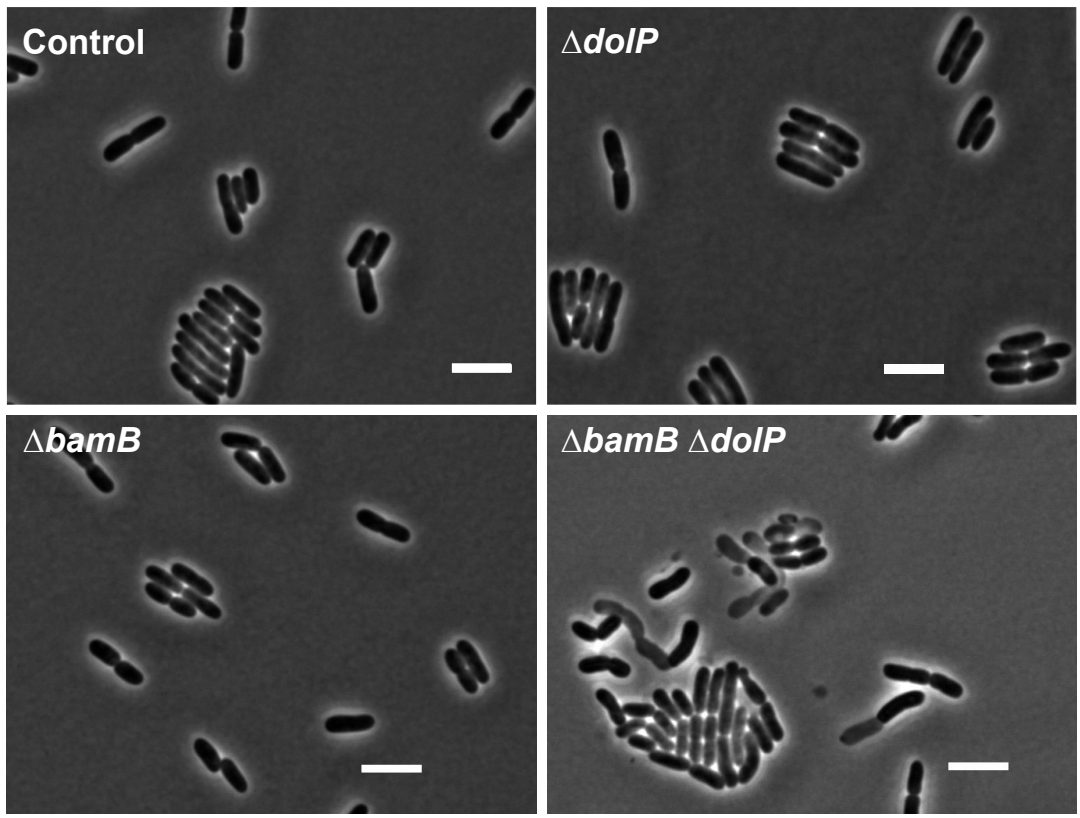

Figure 2. 
A

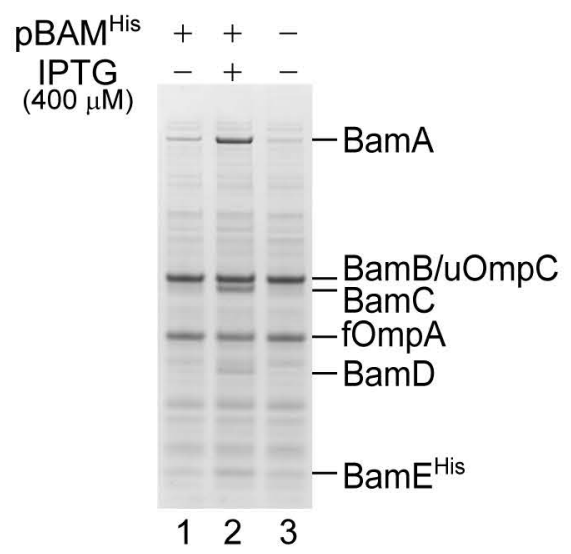

C

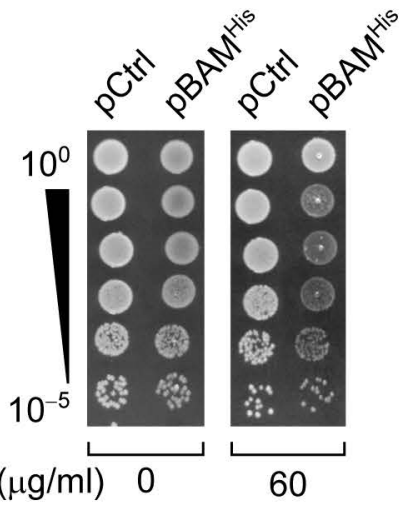

B
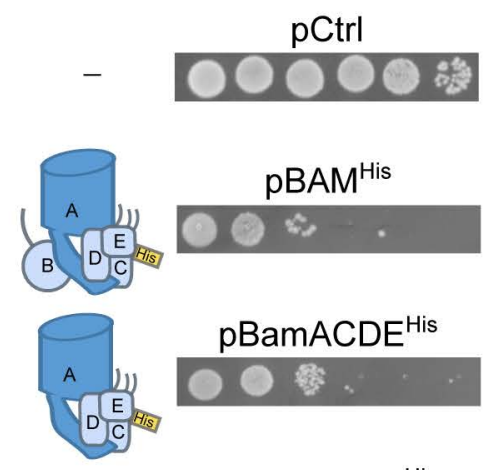

pBAM $^{\text {His }}$

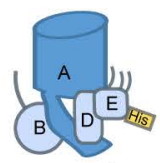

pBamABDE ${ }^{\text {His }}$

pBamACDE ${ }^{\text {His }}$

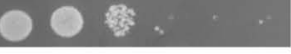

1000
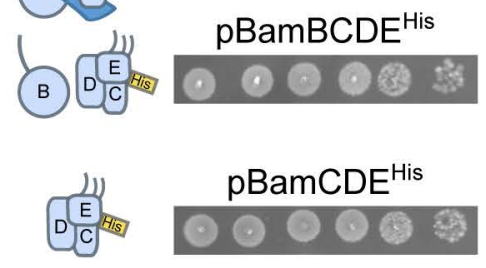

9

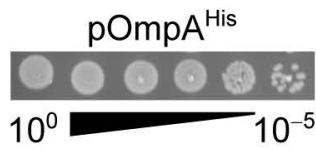

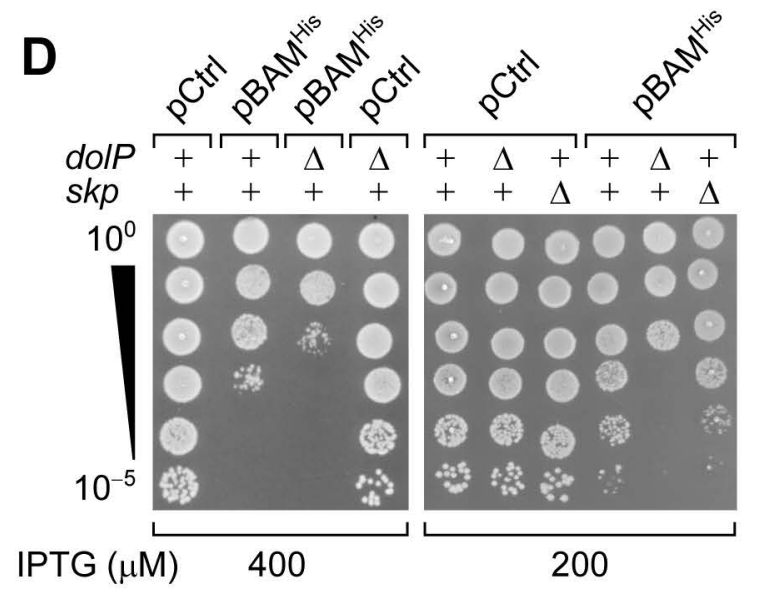

Figure 3. 
A

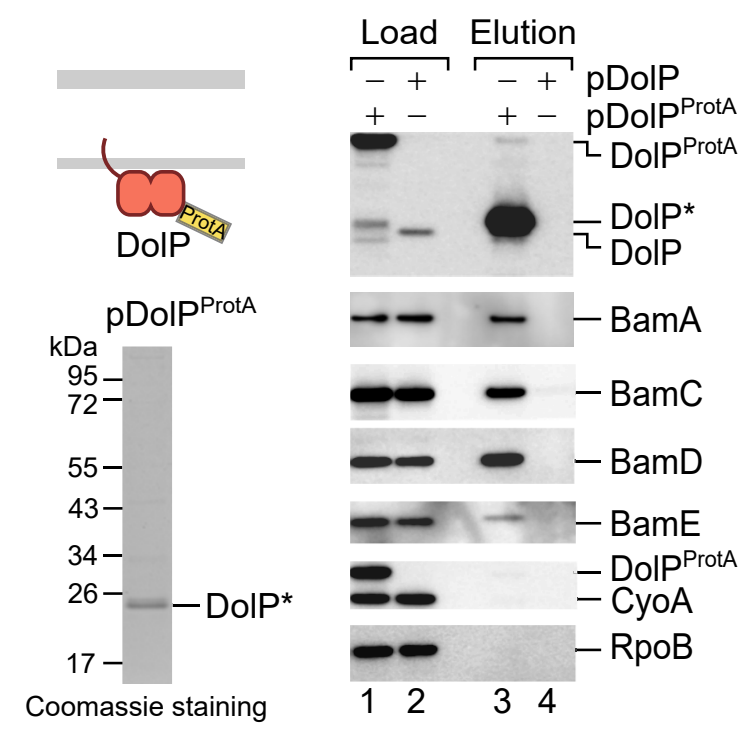

C
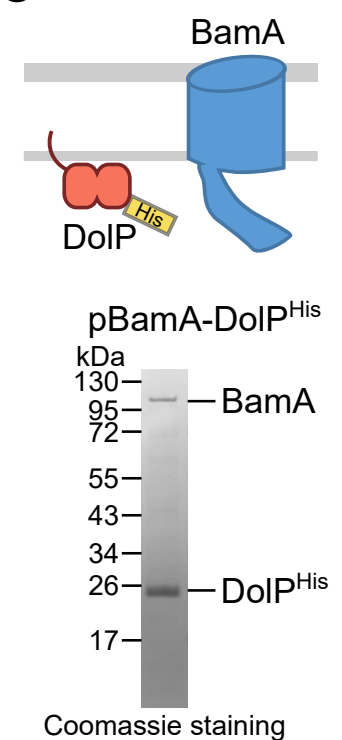

E

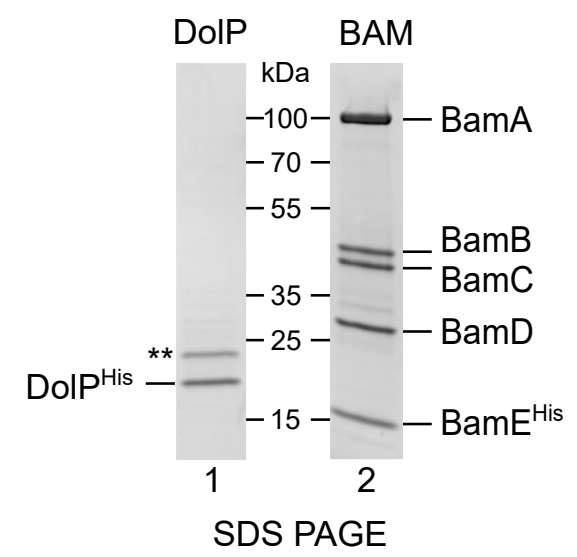

$\mathbf{F}$
B

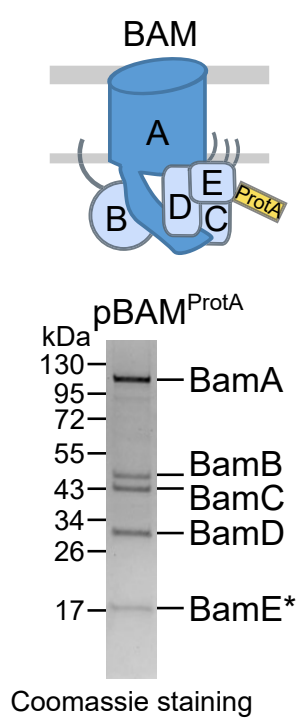

D
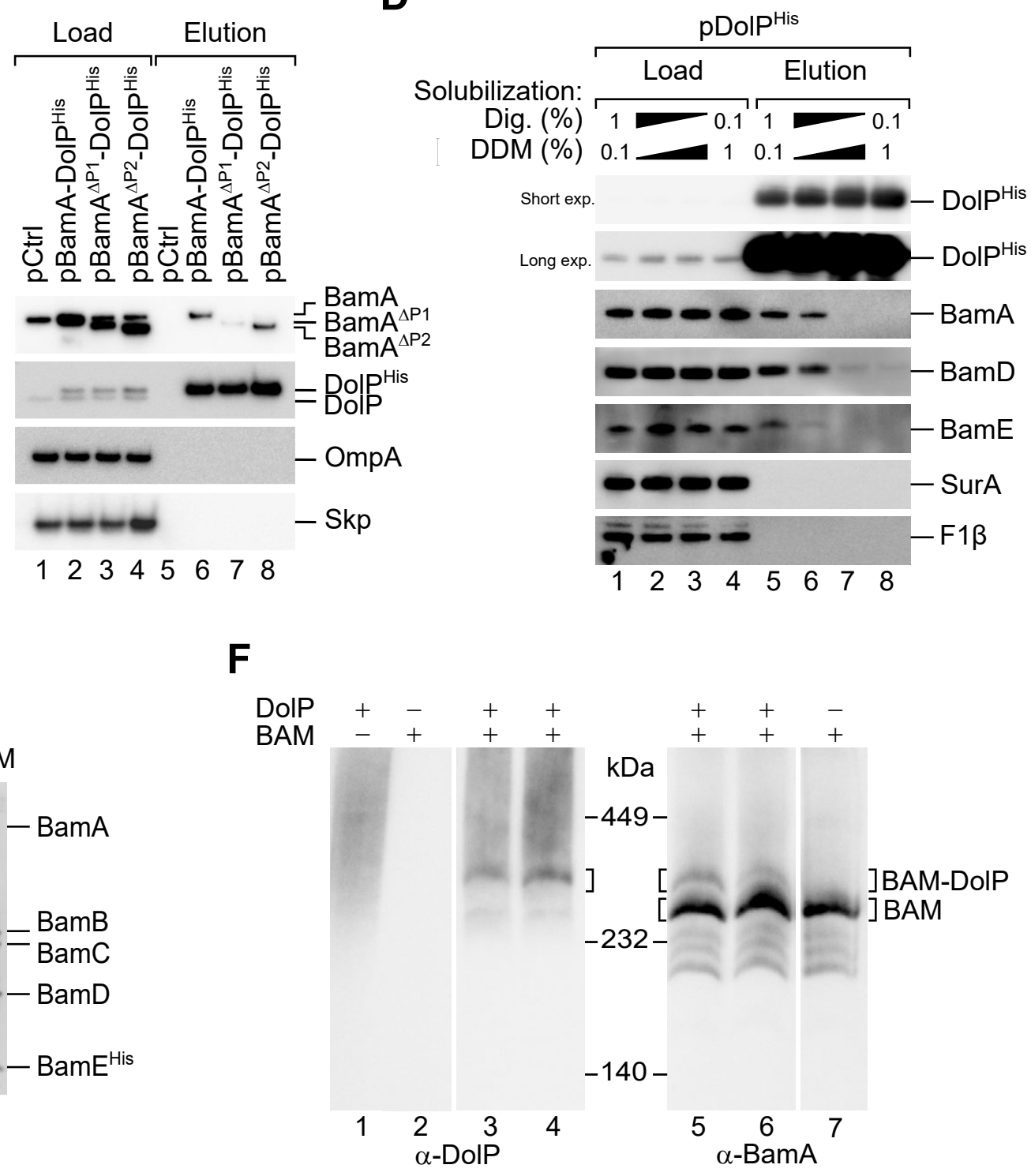

Blue native PAGE

Figure 4. 
A
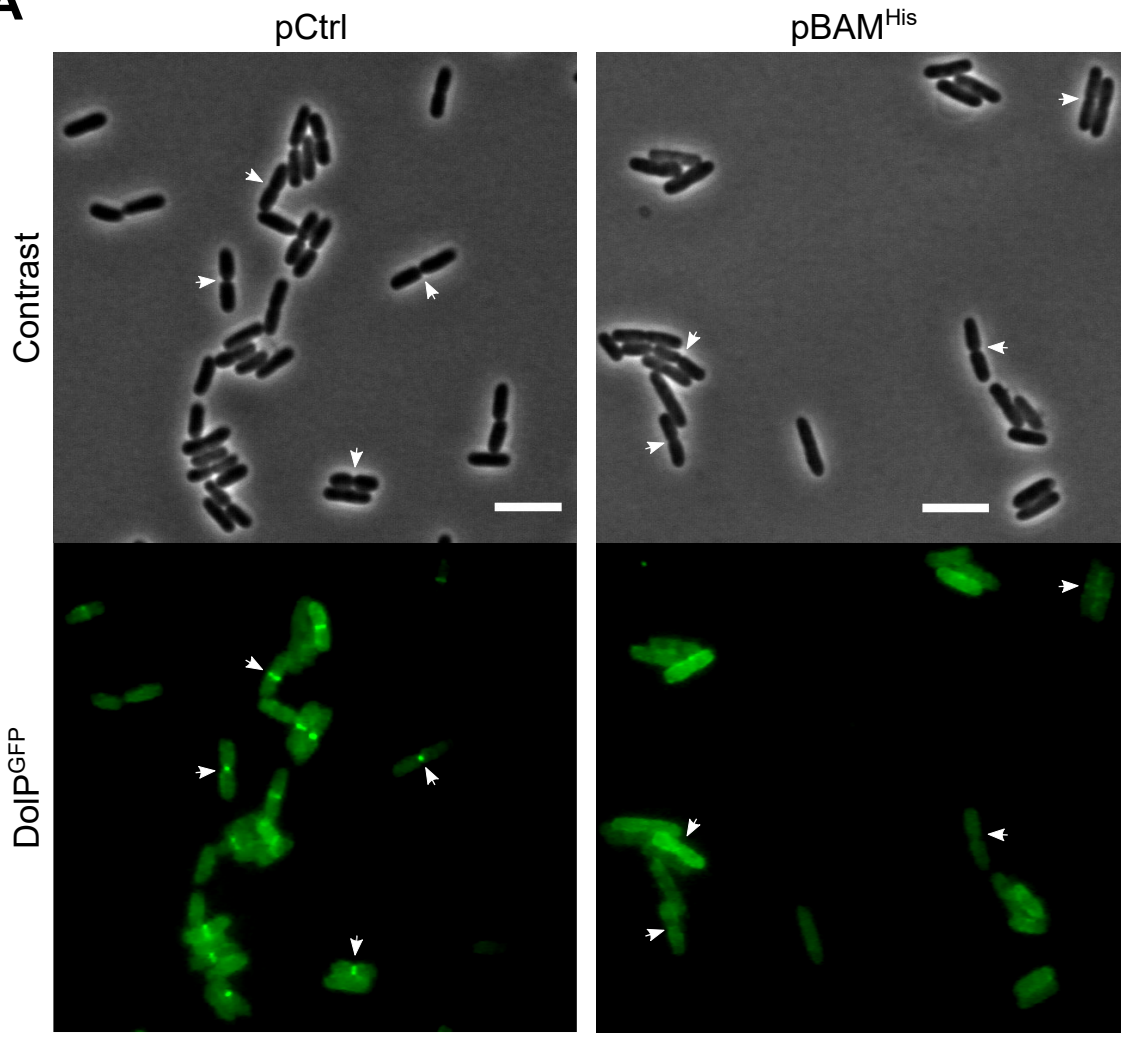

B

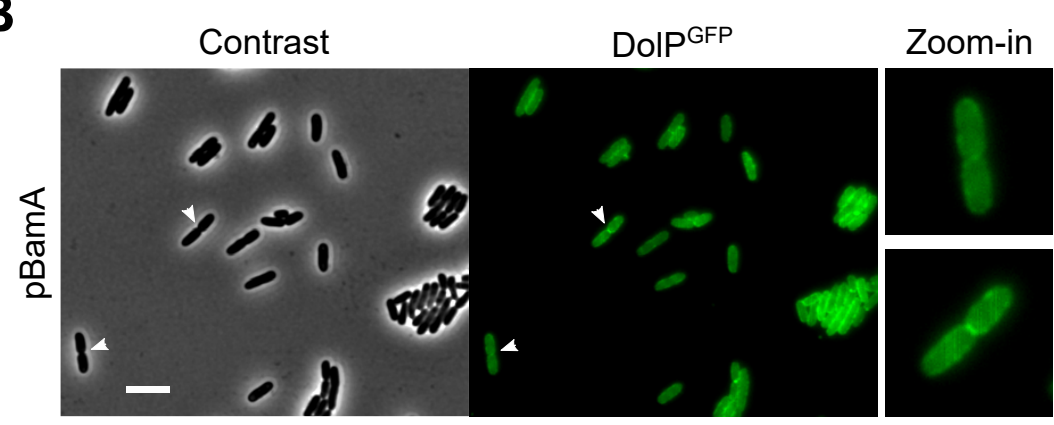

C
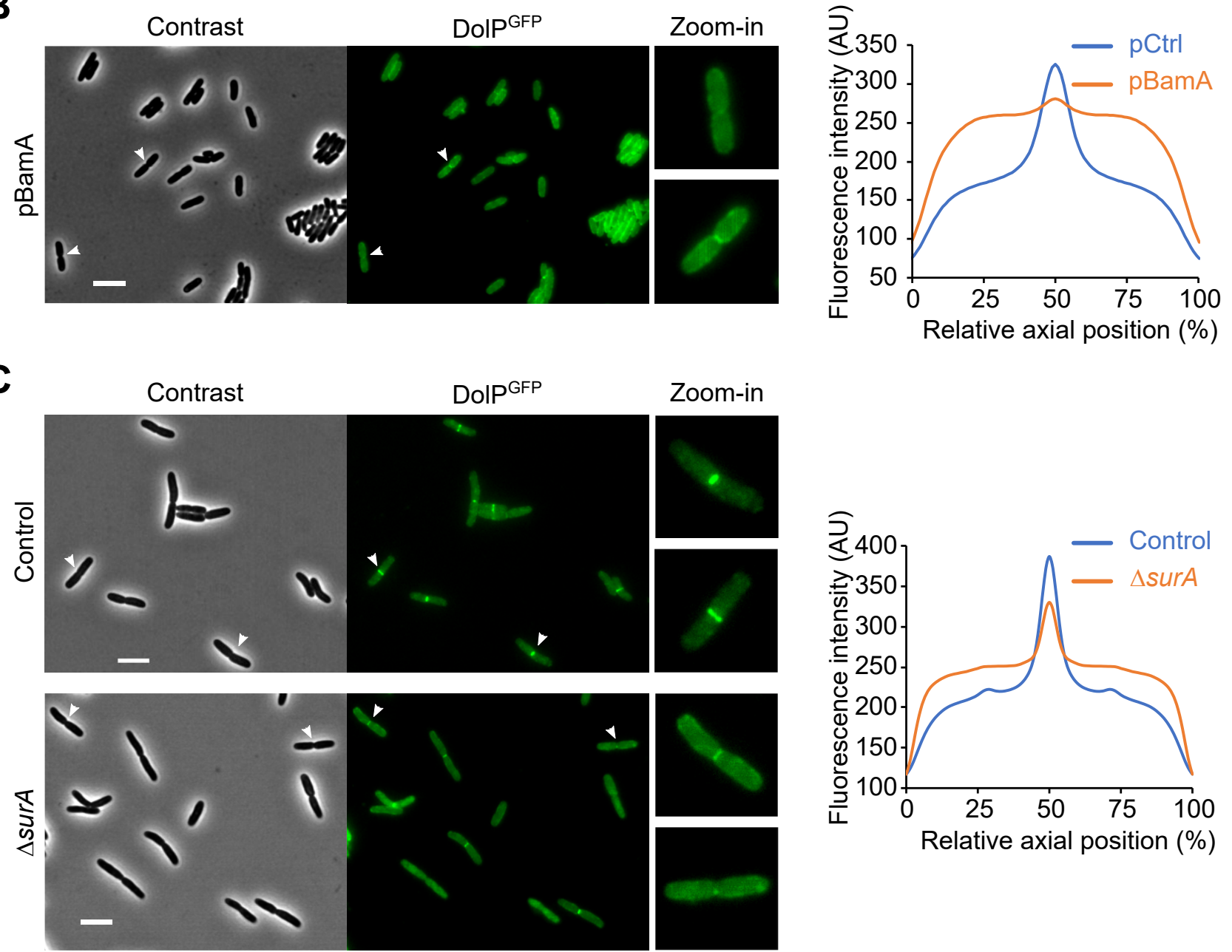

Figure 5. 
A

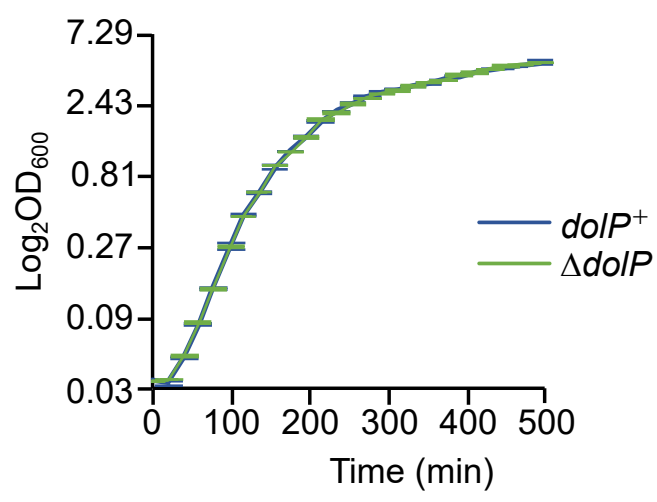

B

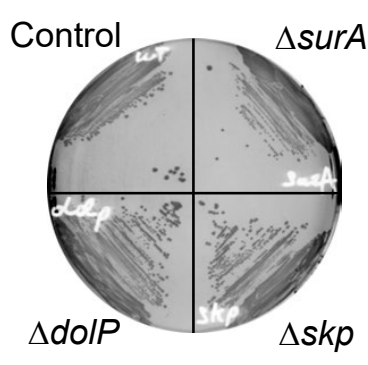

- Vancomycin

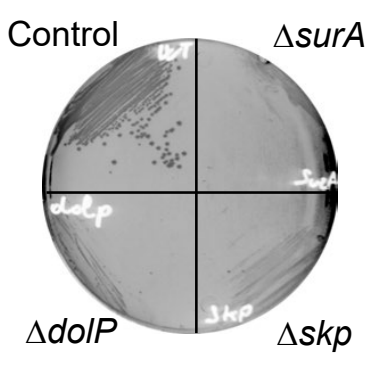

+ Vancomycin $(60 \mu \mathrm{g} / \mathrm{ml})$

C

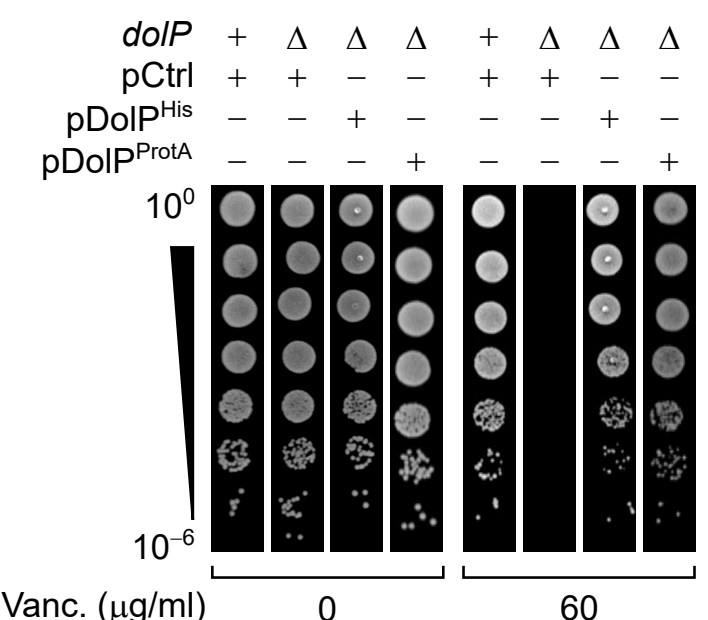

Figure S1. 
bioRxiv preprint doi: https://doi.org/10.1101/2020.09.23.308296; this version posted November 3, 2020. The copyright holder for this

preprint (which was not certified by peer review) is the author/funder. All rights reserved. No reuse allowed without permission.

A


B

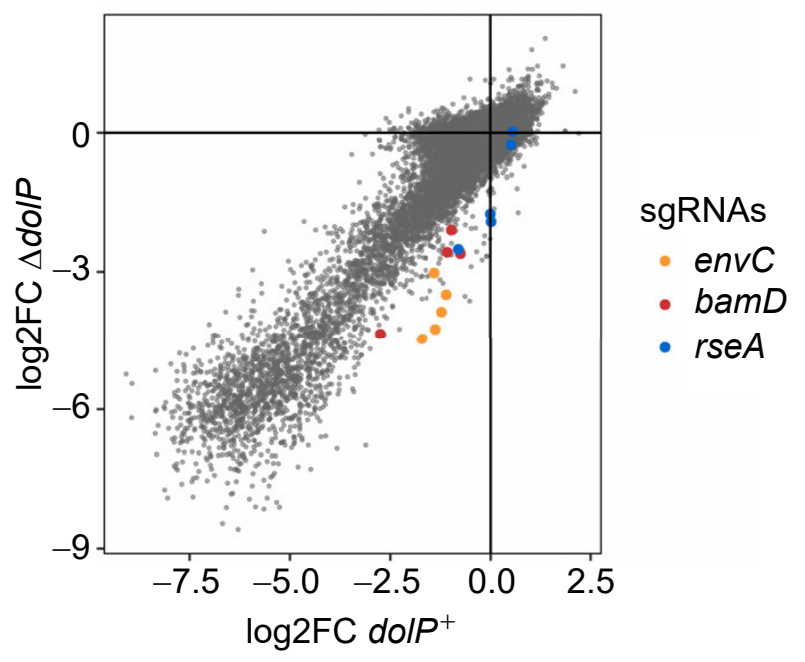

C

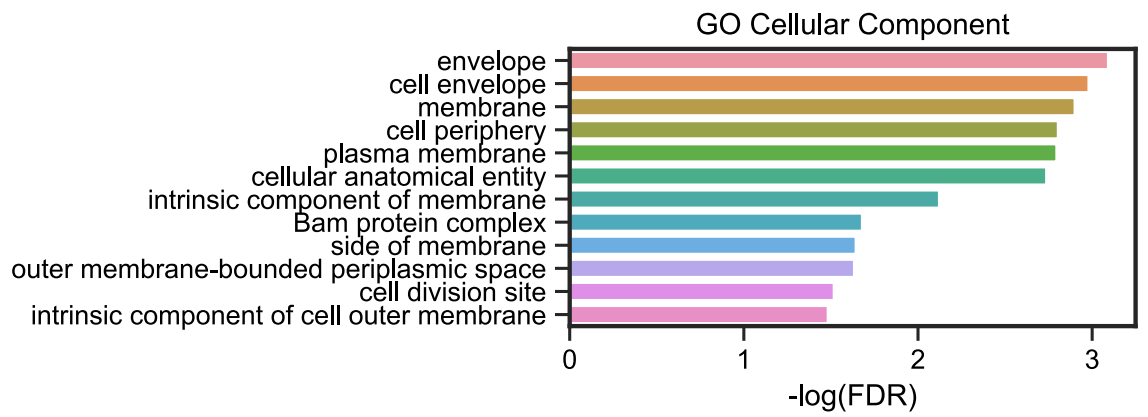

GO Biological Process

cellular protein localization cellular macromolecule localization protein localization

establishment of protein localization

intracellular protein transmembrane transpor

Gram-negative-bacterium-type cell outer membrane assembly

intracellular protein transport

membrane assembly

intracellular transpor

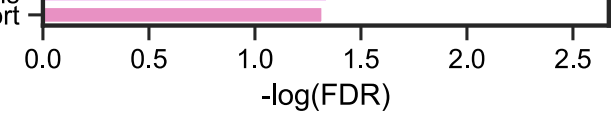

Figure S2. 
A

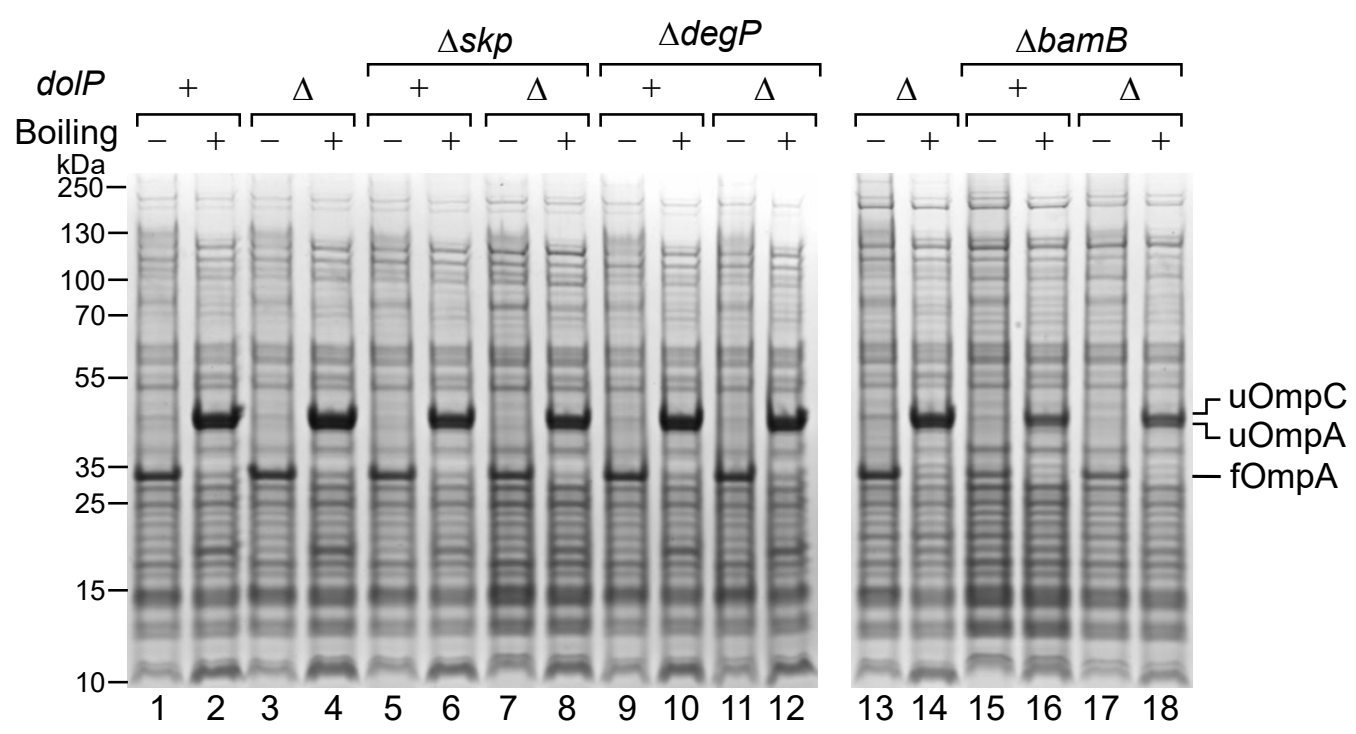

B

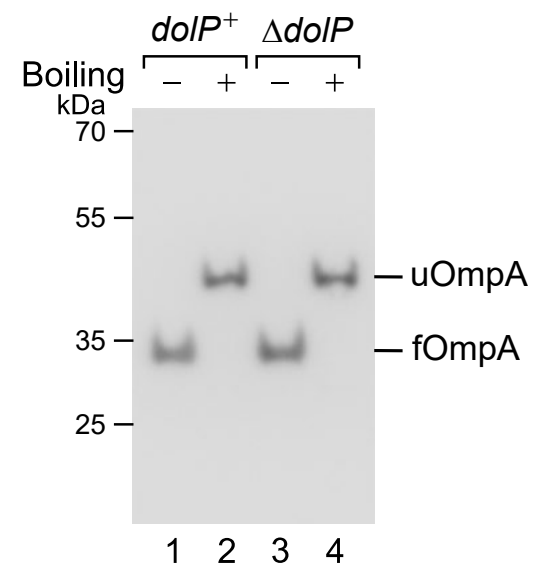

C

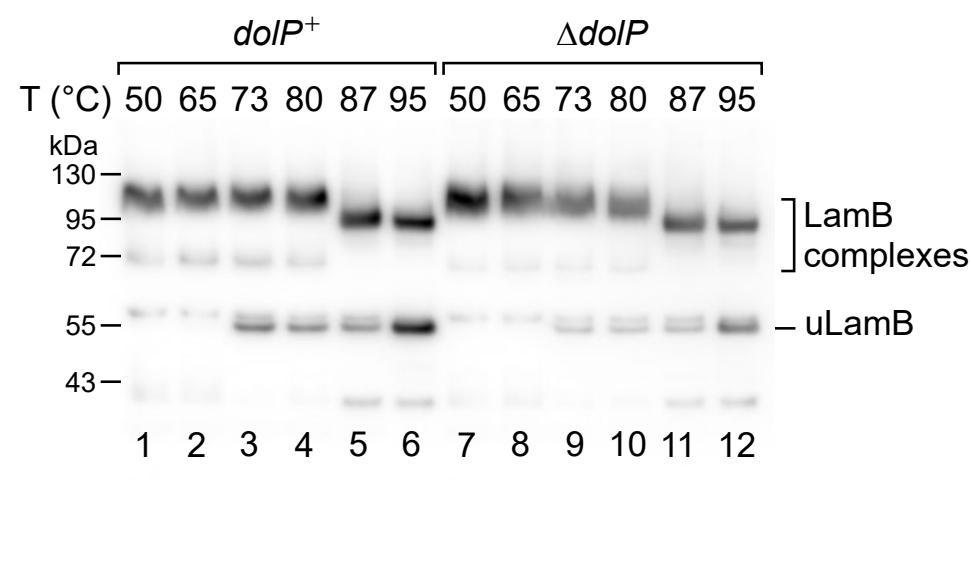

D

\section{$\mathbf{E}$}
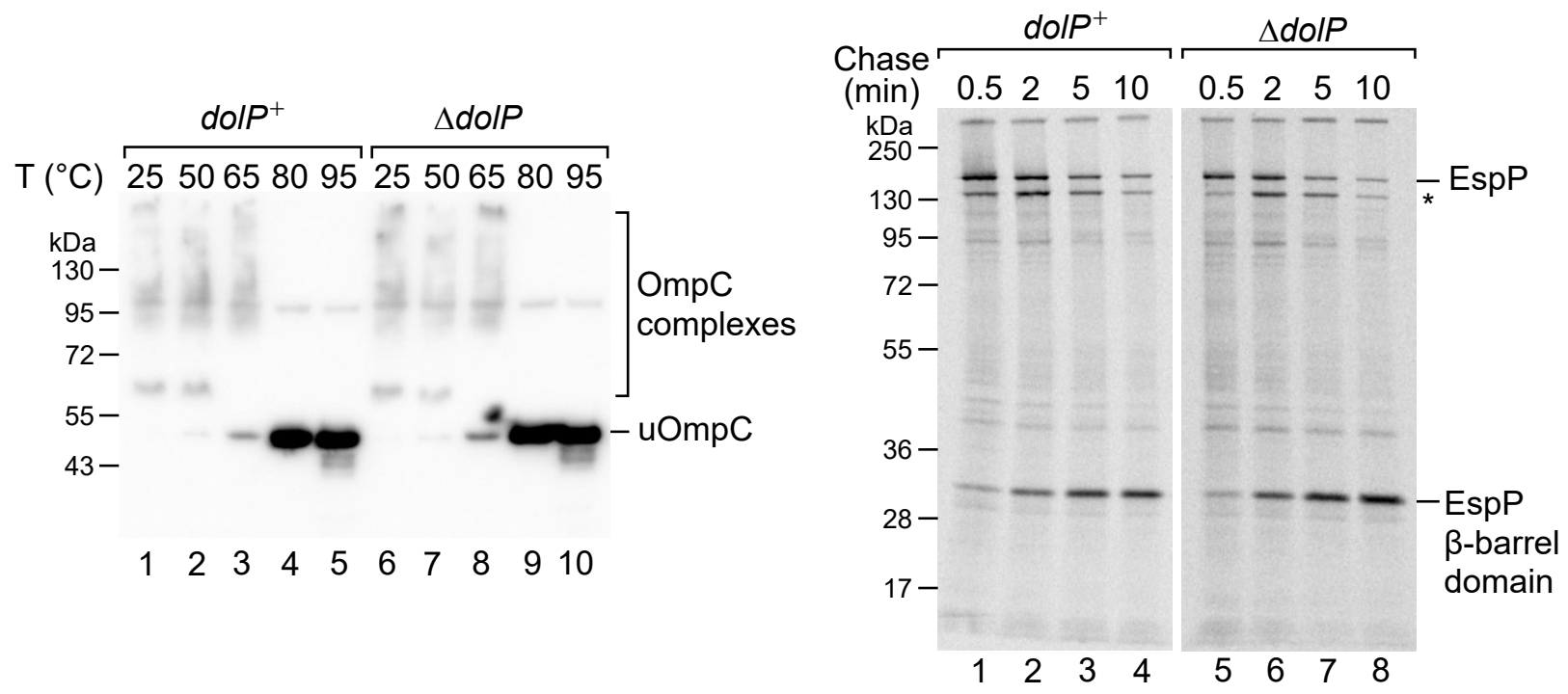
A

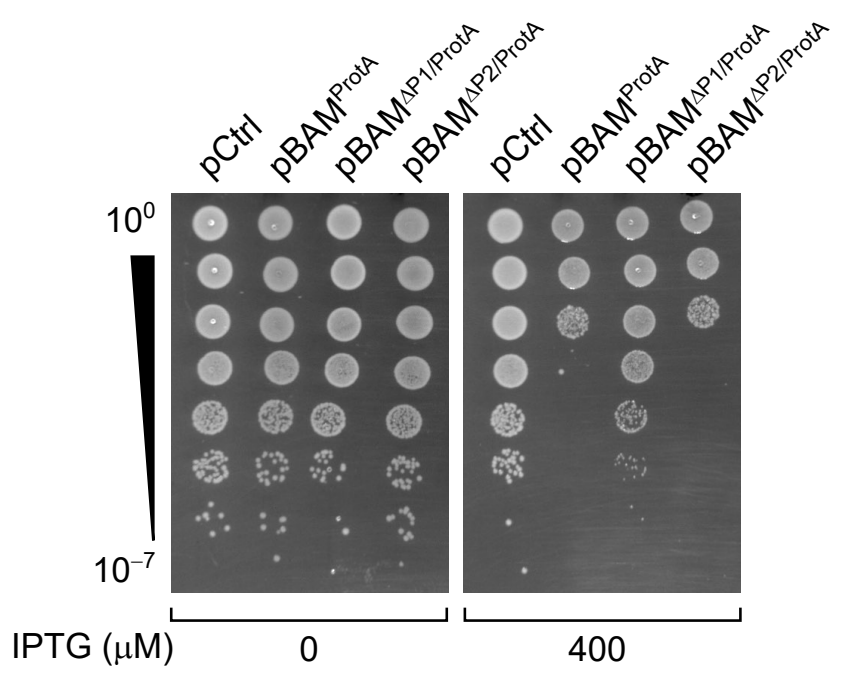

B

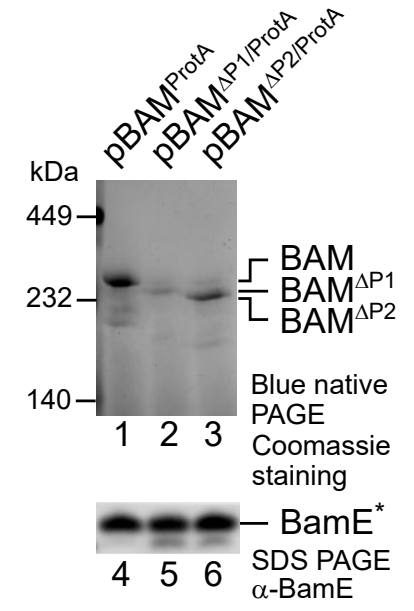

C

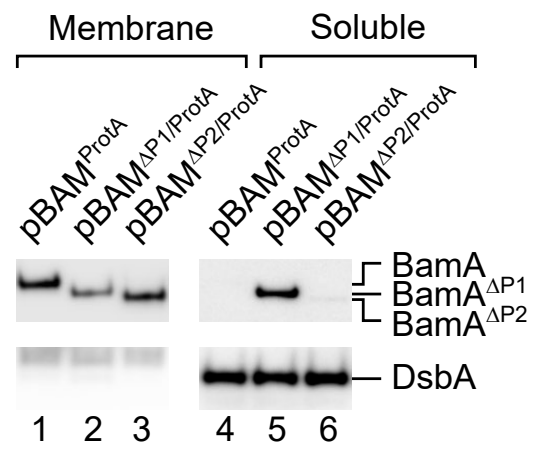

Figure S4. 


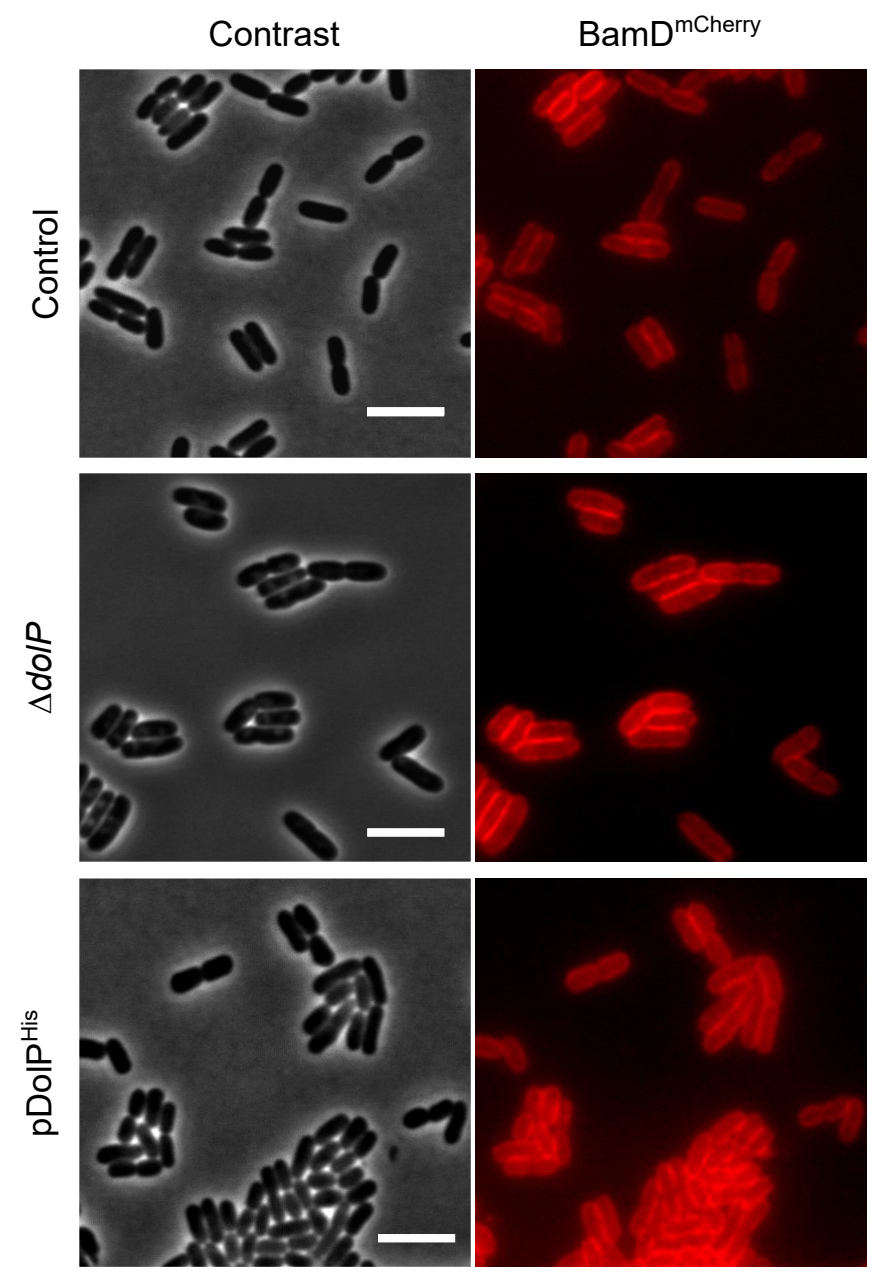

Figure S5. 
A

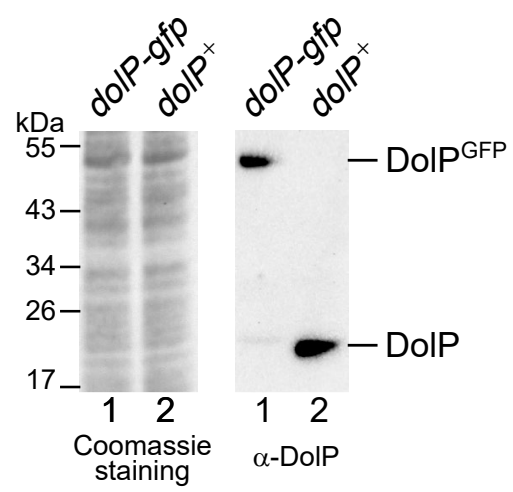

B
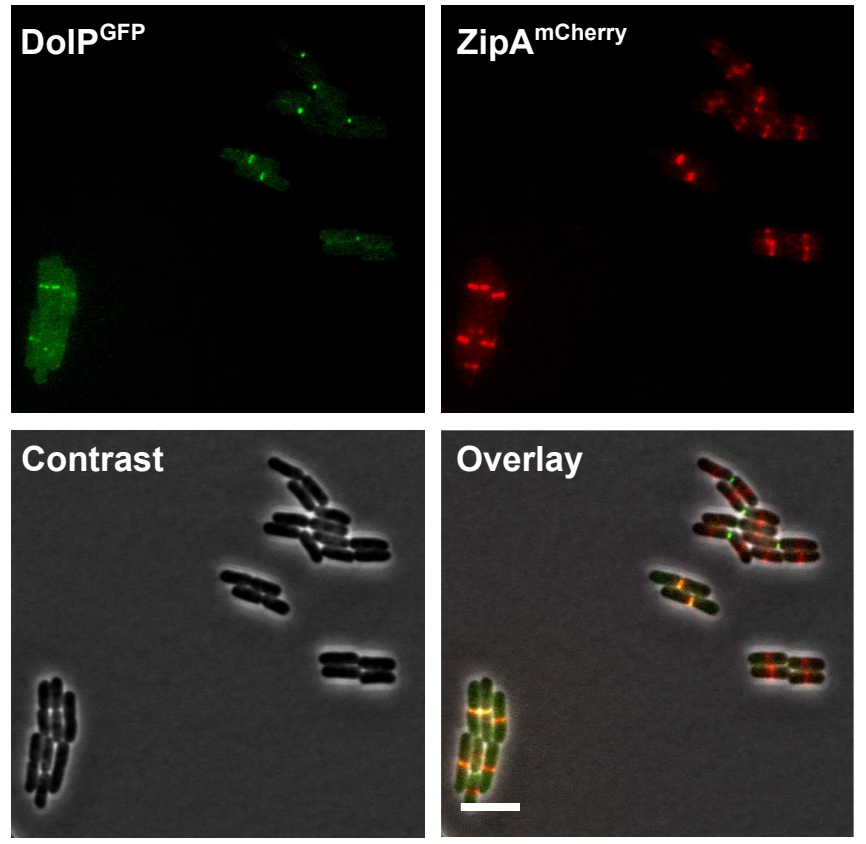

C


Figure S6. 
A
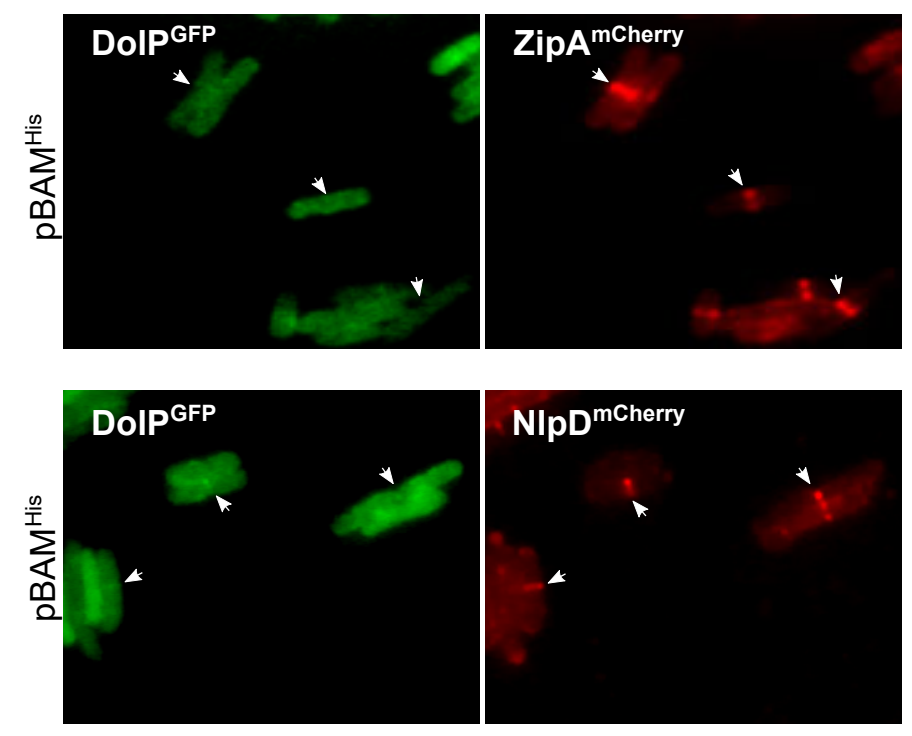

B
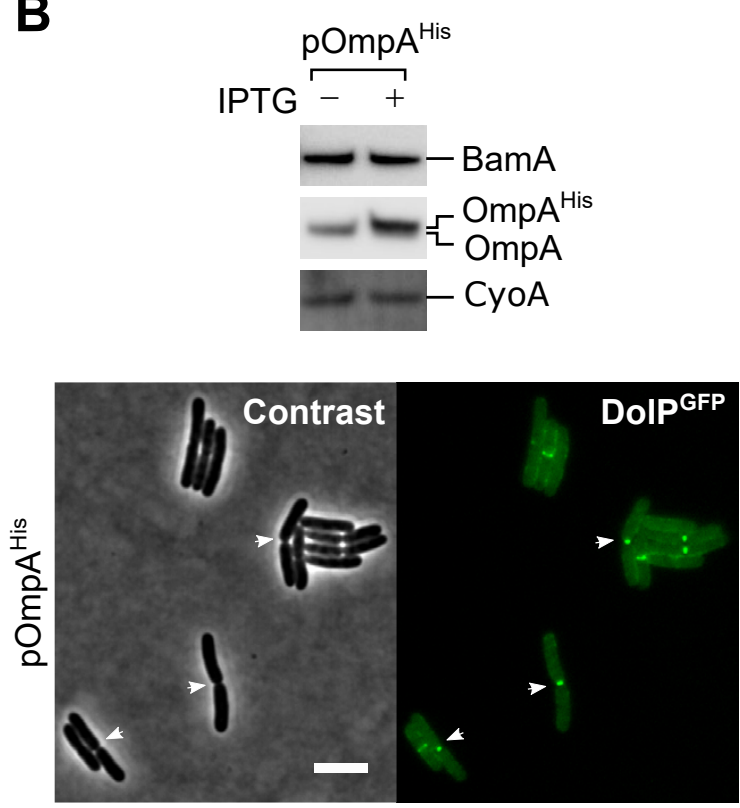

C
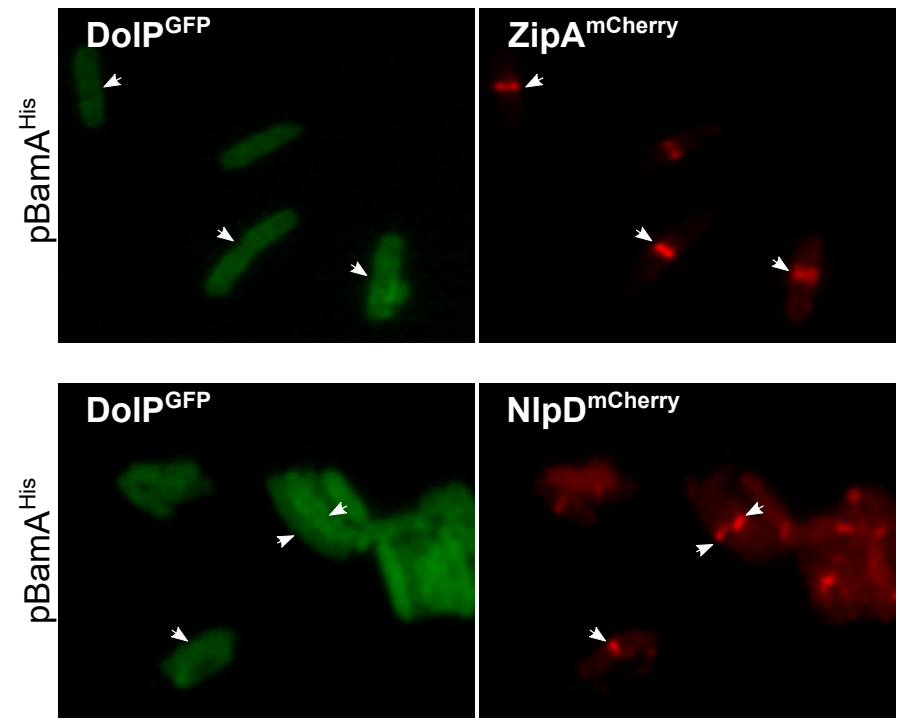

Figure S7. 
A

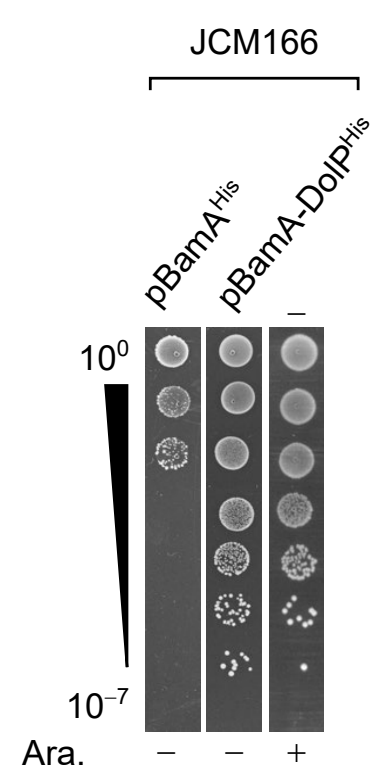

B
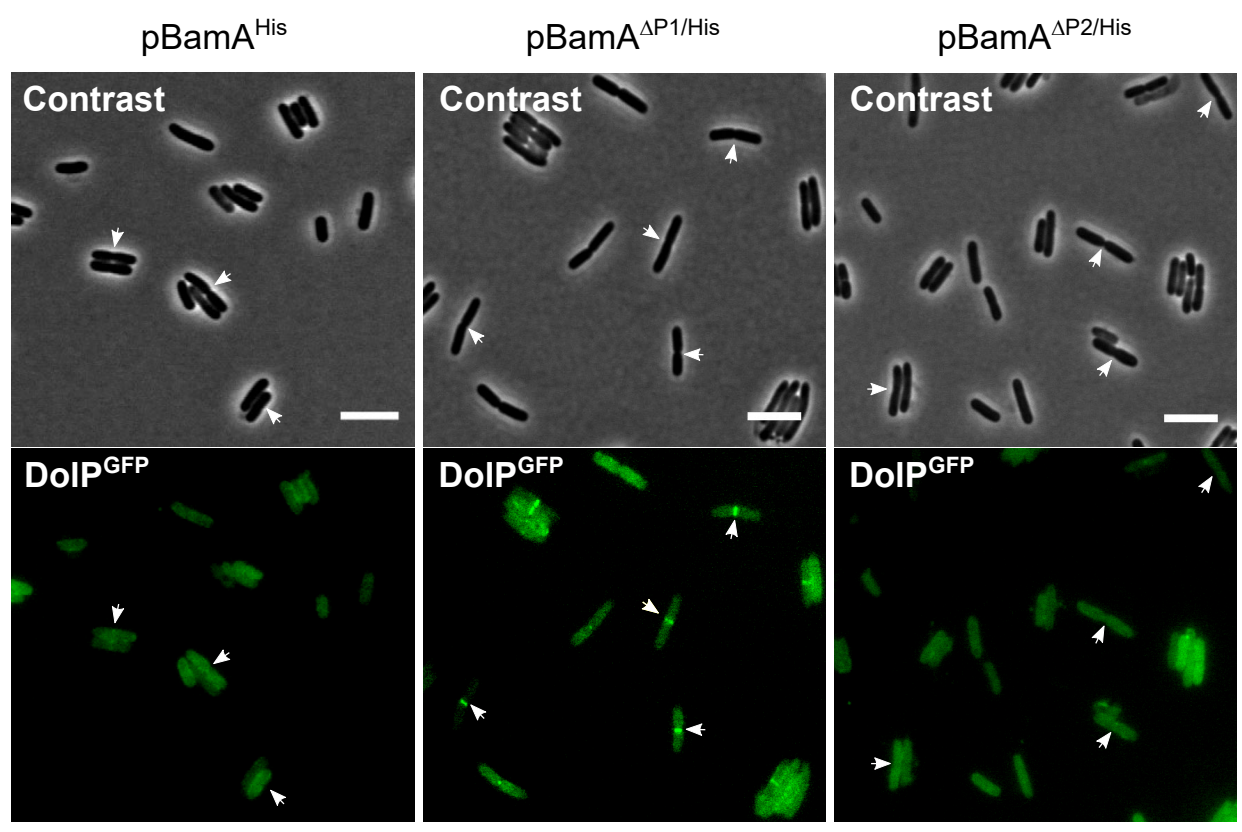

C

D
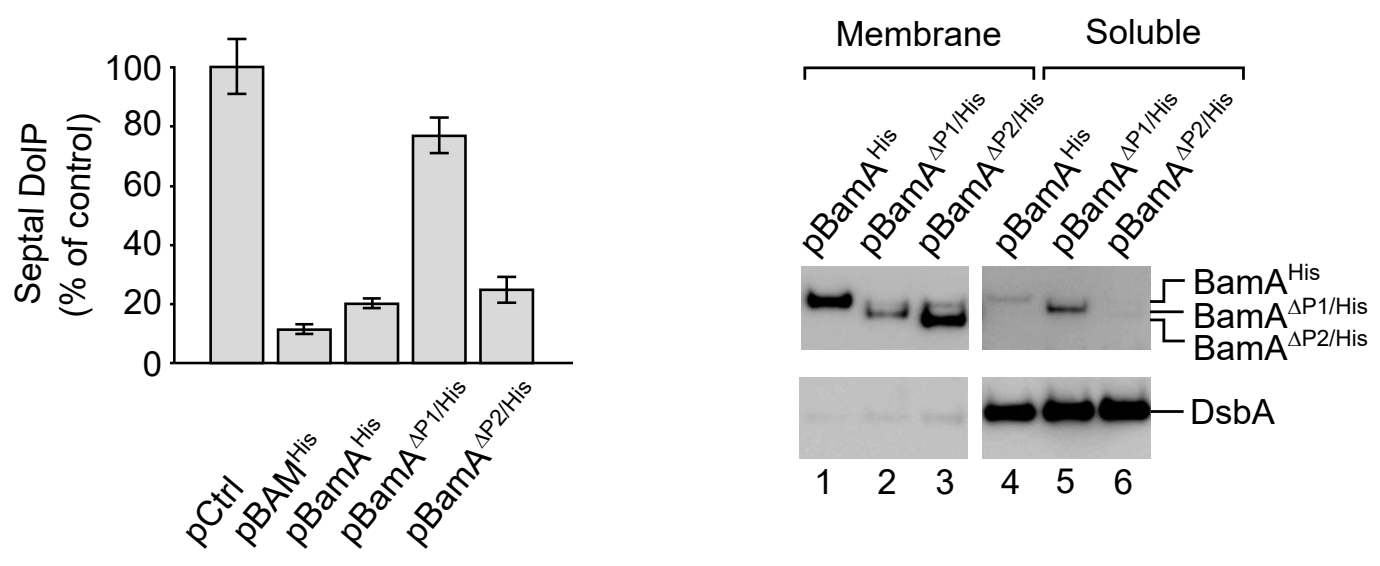

Figure S8. 
A
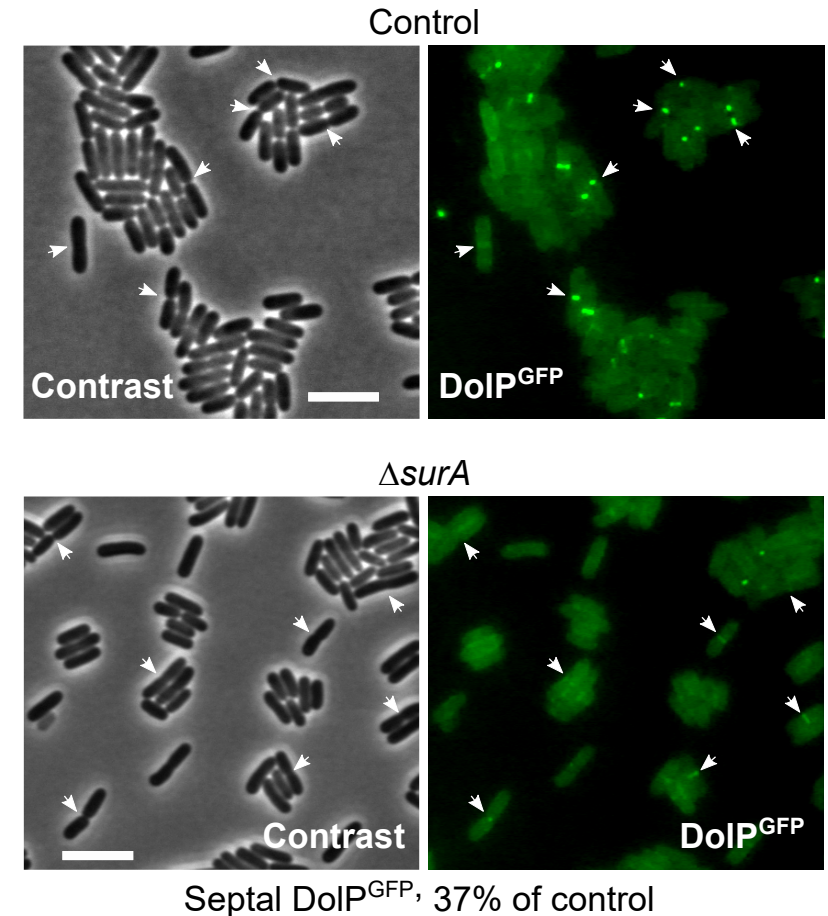

B

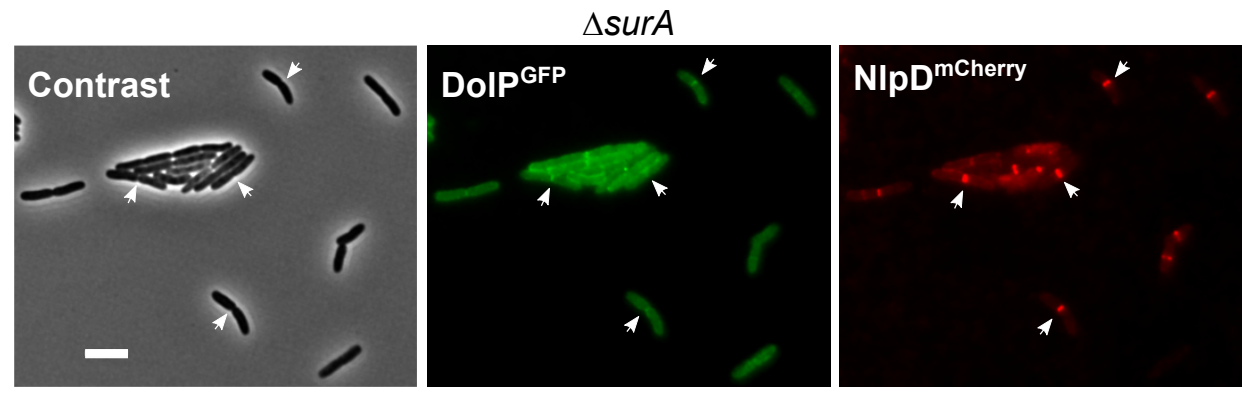

C

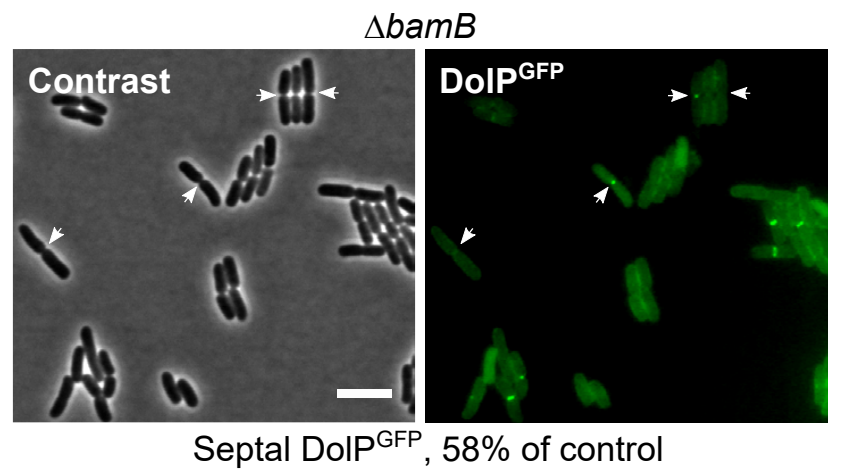

Figure S9. 